\title{
A new leptoceratopsid dinosaur from Maastrichtian-aged deposits of the Sustut Basin, northern British Columbia, Canada
}

\author{
Victoria M. Arbour ${ }^{\text {Corresp., } 1}$, David C. Evans ${ }^{2}$ \\ 1 Department of Knowledge, Royal BC Museum, Victoria, BC, Canada \\ 2 Department of Natural History, Royal Ontario Museum, Toronto, ON, Canada \\ Corresponding Author: Victoria M. Arbour \\ Email address: varbour@royalbcmuseum.bc.ca
}

A partial dinosaur skeleton from the Sustut Basin of northern British Columbia, Canada, previously described as an indeterminate neornithischian, is here reinterpreted as a leptoceratopsid ceratopsian, Ferrisaurus sustutensis, gen. et. sp. nov. The skeleton includes parts of the pectoral girdles, left forelimb, left hindlimb, and right pes. It can be distinguished from other named leptoceratopsids based on the proportions of the ulna and pedal phalanges. This is the first unique dinosaur species reported from British Columbia, and can be placed within a reasonably resolved phylogenetic context, with Ferrisaurus recovered as more closely related to Leptoceratops than Montanoceratops. At 68.2 to 67.2 $\mathrm{Ma}$ in age, Ferrisaurus falls between, and slightly overlaps with, both Montanoceratops and Leptoceratops, and represents a western range extension for Laramidian leptoceratopsids. 
1 A new leptoceratopsid dinosaur from Maastrichtian-aged deposits of the Sustut Basin, northern

2 British Columbia, Canada

3

4 Victoria M. Arbour ${ }^{1}$, David C. Evans ${ }^{2}$

5

6 1Department of Knowledge, Royal BC Museum, Victoria, BC, Canada

$7 \quad$ 2Department of Natural History, Royal Ontario Museum, Toronto, ON, Canada

8

9 Corresponding author:

10 Victoria M. Arbour ${ }^{1}$

11 Email address: varbour@royalbcmuseum.bc.ca

12

13

14

15

16

17

18

19

20

21

22

Peer] reviewing PDF | (2019:06:38350:1:1:NEW 18 Sep 2019) 


\section{ABSTRACT}

24 A partial dinosaur skeleton from the Sustut Basin of northern British Columbia, Canada, previously 25 described as an indeterminate neornithischian, is here reinterpreted as a leptoceratopsid ceratopsian, 26 Ferrisaurus sustutensis, gen. et. sp. nov. The skeleton includes parts of the pectoral girdles, left forelimb, 27 left hindlimb, and right pes. It can be distinguished from other named leptoceratopsids based on the 28 proportions of the ulna and pedal phalanges. This is the first unique dinosaur species reported from 29 British Columbia, and can be placed within a reasonably resolved phylogenetic context, with Ferrisaurus 30 recovered as more closely related to Leptoceratops than Montanoceratops. At 68.2 to 67.2 Ma in age, 31 Ferrisaurus falls between, and slightly overlaps with, both Montanoceratops and Leptoceratops, and 32 represents a western range extension for Laramidian leptoceratopsids. 


\section{INTRODUCTION}

48 The dense boreal forest and thrusted, folded rocks of the Canadian Cordillera present a challenging 49 environment in which to search for dinosaurs, compared to the better exposed and more easily 50 accessible outcrops in the badlands of the prairie provinces. Nevertheless, a dinosaur specimen (RBCM 51 P900) consisting of articulated and disarticulated limb and girdle elements was discovered in 1971 in the 52 remote interior mountains of north-central British Columbia (Fig. 1; Arbour and Graves 2008). These 53 bones were collected by geologist Kenny F. Larsen, who was surveying for uranium along the then in54 construction BC Rail line along the Sustut River, and were later donated to Dalhousie University (Halifax, 55 NS) and subsequently accessioned at the Royal British Columbia Museum in Victoria, BC. Arbour and 56 Graves (2008) described this material and identified it as an indeterminate small-bodied, bipedal neornithischian, possibly representing either a pachycephalosaur or a basal ornithopod similar to Thescelosaurus. Here we provide a new interpretation of this material and argue for its assignment to Leptoceratopsidae as a new genus and species. Leptoceratopsids were short-frilled, hornless ceratopsians with a maximum body length of about two-to-three meters, and form the sister group to all other coronosaurian neoceratopsians (He et al. 2015). They were present in many CampanianMaastrictian aged dinosaur assemblages from Asia and North America, but are generally rare in the fossil record (Ryan et al. 2012, Longrich 2016).

RBCM P900 is one of the only vertebrate fossils yet described from the Sustut Basin and as such is significant for understanding the distribution and evolution of dinosaurs in western North America. A 2017 survey of the field area near the confluence of Birdflat Creek and the Sustut River recovered a fragment of the Cretaceous turtle Basilemys at a location closely matching Larsen's original field notes, suggesting that RBCM P900 most likely derived from the same outcrop (Fig 1; Arbour et al. in press). This work generated new stratigraphic and palynological data that allows the provenance of this important skeleton to be documented in detail for the first time. RBCM P900 is likely from the Tango Creek Formation, rather that the Brothers Peak Formation as originally reported, and the new palynological data suggest that the specimen is late Maastrichtian in age, allowing its morphology and biogeography to be understood in a more detailed temporal context and compared to more closely related leptoceratopsids. 
76 Institutional abbreviations: LACM, Los Angeles County Museum; MOR - Museum of the Rockies,

77 Bozeman, Montana, USA; RBCM - Royal BC Museum, Victoria, British Columbia, Canada; Raymond M.

78 Alf Museum of Paleontology, Claremont, California, USA; ROM - Royal Ontario Museum, Toronto,

79 Ontario, Canada; TMP - Royal Tyrrell Museum of Palaeontology, Drumheller, Alberta, Canada; UALVP -

80 University of Alberta, Edmonton, Alberta, Canada; CMN, Canadian Museum of Nature, Ottawa, Ontario,

81 Canada.

82

METHODS

84

The electronic version of this article in Portable Document Format (PDF) will represent a published work according to the International Commission on Zoological Nomenclature (ICZN), and hence the new names contained in the electronic version are effectively published under that Code from the electronic edition alone. This published work and the nomenclatural acts it contains have been registered in ZooBank, the online registration system for the ICZN. The ZooBank LSIDs (Life Science Identifiers) can be resolved and the associated information viewed through any standard web browser by appending the LSID to the prefix http://zoobank.org/. The LSID for this publication is: urn:Isid:zoobank.org:pub:D1C60A34-3632-43AD-BCE0-C93D5E26D1B0. The online version of this work is archived and available from the following digital repositories: PeerJ, PubMed Central and CLOCKSS. No permits were required for this study and all fossils are permanently accessioned in repositories.

RBCM P900 was compared to ceratopsian, pachycephalosaurid, ornithopodan, and parksosaurid dinosaurs in various collections (SI 1) and the literature, and comparative measurements are provided in SI 2. Photogrammetric digital models of the specimen (SI 3) were created using Agisoft Metashape 1.5.4 using between 50 and 200 digital photos (in RAW format, converted to TIFFs) taken with a Canon Rebel XTi.

We assessed the phylogenetic position of RBCM P900 using the character-taxon matrix for ceratopsians presented by He et al. (2015), derived from previous matrices built by Farke et al. (2014), Ryan et al. (2012), and Makovicky (2001). Our matrix includes 34 taxa and 165 characters (SI 1 and 4) and was compiled in Mesquite v3.04 build 725 (Maddison and Maddison 2011). We added three new characters (characters 163-165) based on observations made over the course of this study. We also tested the position of RBCM P900 using the character-taxon matrix presented by Morschhauser et al. (2019), with no modifications to the matrix other than the addition of RBCM P900. We performed a cladistic 
106 parsimony analysis on both matrices using the Traditional Search option in TNT v1.5 (Goloboff et al.

107 2008); all characters were treated as unordered and of equal weight, and we used the tree bisection 108 reconnection (TBR) swapping algorithm with 1000 replications.

109

110 SYSTEMATIC PALAEONTOLOGY

111 DINOSAURIA Owen, 1842

112 ORNITHISCHIA Seeley, 1888

113 NEORNITHSICHIA Cooper, 1985

114 MARGINOCEPHALIA Sereno, 1986

115 CERATOPSIA Marsh, 1890

116 NEOCERATOPSIA Sereno, 1986

117 CORONOSAURIA Sereno, 1986

118 LEPTOCERATOPSIDAE Nopcsa, 1923

119 FERRISAURUS SUSTUTENSIS gen. et sp. nov. urn:Isid:zoobank.org:act:A7F4267C-8CC6-49B6-8E52$120 \quad 2 \mathrm{C} 2148929 B 14$

121 Diagnosis: Ferrisaurus can be differentiated from other known leptoceratopsids based on the following 122 unique combination of characters: penultimate pedal phalanges in digits III and IV are equal or subequal 123 in proximodistal length compared to the length of the preceding phalanx, rather than shorter as in all 124 other leptoceratopsids for which these elements are preserved except possibly USNM 13863 125 (Cerasinops); astragalus and tibia coossified, unlike all other leptoceratopsids except for AMNH 5464 126 (Montanoceratops); distal end of ulna broader relative to radius length than in Leptoceratops; distal end 127 of ulna medially bowed, unlike the straight ulna of the penecontemporaneous Maastrichtian taxa 128 Leptoceratops and Montanoceratops, but similar to Cerasinops and Prenoceratops from the Campanian.

129 Etymology: "Iron lizard", from Latin ferrum (=iron) and Greek sauros (=lizard), in reference to the 130 specimen's discovery along a railway line, and sustutensis in reference to its provenance near the Sustut 131 River and within the Sustut Basin. 
132 Holotype: RBCM P900, a partial skeleton consisting of a partial right coracoid, fragmentary left scapula, 133 complete left radius, distal portion of the left ulna, associated distal two thirds of the left tibia and fibula 134 and coossified astraglus and ?calcaneum, partial articulated digits III and IV of the right pes, and an 135 unprepared block removed from the posterior surface of the tibia that appears to contain four 136 metatarsals, presumably from the left pes. Previously catalogued as RBCM.EH2006.019.0001 to 137 RBCM.EH2006.019.010 and published under RBCM.EH2006.019 by Arbour and Graves (2008).

138 Locality: RBCM P900 was discovered near the confluence of Birdflat Creek and the Sustut River in the 139 Sustut Basin (Fig. 1); the bones were found loose in the rubble during construction along the BC Rail line, 140 which has since been abandoned. Fieldwork in the Sustut Basin in 2017 provided strong support for the 141 relocation of the original collection site a few hundred meters from the confluence of the Sustut River 142 and Birdflat Creek (Arbour et al. in press); exact GPS coordinates are on file at the Royal BC Museum.

143 Formation and Age: Tatlatui Member, Tango Creek Formation, Sustut Group. Palynomorphs recovered 144 from the presumed holotype locality included the Maastrichtian marker taxon Pseudoaquilapollenites 145 bertillonites, indicating an age of approximately 68.2 to 67.2 Ma for the site (Arbour et al. in press).

LSID: urn:Isid:zoobank.org:act:A7F4267C-8CC6-49B6-8E52-2C2148929B14

\section{DESCRIPTION AND COMPARISON}

149 RBCM P900 includes multiple elements in articulation, including the tibia and fibula, several pedal phalanges, and potentially the metatarsals (Fig. 2). The presence of metatarsals in a block of sediment removed from the posterior face of the distal tibia suggests that the skeleton may have been fully articulated in situ. The bones do not appear to have suffered from brittle or plastic deformation, but they have been recrystallized, obscuring the original internal bone textures.

We reinterpret RBCM P900 as a leptoceratopsid based on several aspects of the preserved phalanges. The non-ungual phalanges are blockier and more robust in comparison to most orodromines (e.g. Orodromeus MOR 623B), parksosaurids (e.g. Parksosaurus ROM 804), and pachycephalosaurids (e.g. Stegoceras UALVP 2). The dorsal surface of the posterior articular surface in RBCM P900 is more strongly pointed, and overlaps the preceding phalanx more extensively, than in other small ornithischians with ginglymoid phalanges from similar stratigraphic and geographic ranges, such as parksosaurids (e.g. 
161 surfaces, and narrow, pointed unguals, also exclude identifications of this specimen as a juvenile

162 ceratopsid (e.g. Chasmosaurus UALVP 52613) or hadrosaurid (e.g. Edmontosaurus annectens, LACM

16323504 (Prieto-Marquez, 2014), RAM 7150 (Zheng et al. 2011), Lambeosaurinae indet., TMP

164 1998.058.0001). The relatively long and robust forelimb compared to the hindlimb, as indicated by the

165 proportions of the radius and tibia, exclude RBCM P900 from being assigned to Thescelosauridae and

166 Pachycephalosauria. The preserved elements of RBCM P900 are comparable in size to large

167 leptoceratopsid specimens like Cerasinops MOR 300 and Leptoceratops CMN 8889.

168

\section{Pectoral Girdle}

170

171

172

173

174

175

176

177

178

179

180

181

182

183

184

185

186

187

188

189

190

Arbour and Graves (2008:Fig. 2:G, H) were unable to identify a thin, gently curved element of RBCM P900, which we reinterpret here as a fragmentary right coracoid (Fig. 3A). Most of the edges are broken, but the angle of the sternal process is complete and part of the anterior edge is complete. The morphology of this bone compares well with the complete coracoids of Leptoceratops CMN 8889 (Fig. 3B); the coracoids of most other Laramidian leptoceratopsids are incomplete and cannot be compared with RBCM P900. As in Leptoceratops, RBCM P900 had a pronounced, sharply pointed sternal process at the anterior and ventral end of the coracoid. The anterior edge of the coracoid in RBCM P900 appears straighter compared to the more curved edge in CMN 8889 (Leptoceratops), but without comparable material from other taxa it is difficult to assess whether or not this is within the range of intraspecific variation or a taxonomic difference.

A fragmentary flattened bone was interpreted as a possible rib by Arbour and Graves (2008: Fig. 2E,F) and is reinterpreted here as part of the left scapula (Fig. 3C, D), representing a section near the midpoint of the scapular blade. It has a teardrop-shaped cross section on one side and rapidly narrows to a thin oval cross-section on the other side. The teardrop-shaped outline at one end precludes identification of this element as a rib shaft, and ribs for this individual would have been much smaller and less robust, whereas the proportions are more in line with the scapula of a leptoceratopsid with hindlimb proportions of this size. The ventral edge of the fragment is straight, and the dorsal edge is markedly concave. The scapulae of Montanoceratops (MOR 452) and Prenoceratops (TCM 2003.1.9 and TCM 2003.1.11; Fig. 3F) are relatively straight along their dorsal lengths, whereas the scapulae of Cerasinops (MOR 300, Fig. 3E) and Leptoceratops (CMN 8889) are more concave dorsally in lateral view. 
191 Forelimb

192 We agree with the identification of the radius by Arbour and Graves (2008: Fig. 2C,D). The radius is a 193 relatively simple rod-shaped bone with gently expanded proximal and distal ends and a shaft that is 194 triangular in cross section (Fig. 4A-D; Table 1). Overall, the radius of RBCM P900 is very similar to that of 195 Leptoceratops (Brown 1914; Fig. 4E), and it differs only in subtle aspects. The proximal end in RBCM $196 \mathrm{P} 900$ is less cup-shaped compared to Leptoceratops (CMN 8889), and the shaft lacks the prominent 197 protuberance present near the midpoint in Leptoceratops (AMNH 5205; Brown 1914), although a light 198 distal tuberosity is present as in AMNH 5205. The preserved radii of Cerasinops (MOR 300; Fig. 4F) lack 199 distal and proximal ends, but preserve straight shafts lacking any bulges or tuberosities.

200 We reinterpret the bone previously identified by Arbour and Graves (2008: Fig. 2) as the proximal half of 201 a humerus as a partial right ulna including the distal end (Fig 5A,B; Table 1). The absence of a prominent 202 deltopectoral crest or rounded humeral head is inconsistent with its identification as a humerus. The 203 ulna is incomplete proximally, but the shaft is expanded towards the broken proximal end. Based on the 204 proportions of the radius length to ulna length in Leptoceratops, Montanoceratops, and to a lesser 205 extent Cerasinops ( $\mathrm{SI} 2$ ) where the radius is $75-80 \%$ of the length of the ulna, the ulna of RBCM P900 206 may have been $170-180 \mathrm{~mm}$ in total length. The proximal expansion of the ulna occurs approximately $207100 \mathrm{~mm}$ from the base of this element in RBCM P900, compared to about $120 \mathrm{~mm}$ in CMN 8889 208 (Leptoceratops; about 59\% of the total length from the base), $96 \mathrm{~mm}$ in TCM 2003.1.8(Prenoceratops; $20967 \%$ of the length), and $125 \mathrm{~mm}$ in MOR 300 (Cerasinops; 62\% of the length). Extrapolating a total 210 length for the ulna of RBCM P900 based on these proportions yields a total length of $150-170 \mathrm{~mm}$.

211 Comparing the width of the distal ulna to the length of the radius, the ulna of RBCM P900 was

212 proportionately wider compared to other leptoceratopsids (Fig 5, SI 2), giving it a stouter appearance.

213 The ulna shaft is a flattened oval in cross-section, and the distal end is flat and only moderately 214 expanded. A diagnostic character for Cerasinops proposed by Chinnery and Horner (2007) is the strong 215 medial bend of the distal part of the ulna. The distal ulna of RBCM P900 is also medially deflected (Fig. $2165 G)$, with the posterior edge more strongly curved than the anterior edge. The postcrania of the 217 bonebed material of Prenoceratops was not previously described by Chinnery (2004), but examination 218 of TCM 2003.1.8, a right ulna (Fig. 5H), indicates that Prenoceratops also had a medial bend to the distal 219 ulna. The ulna is straight in this region in Leptoceratops (CMN 8889) and Montanoceratops (MOR 542; 220 Fig. 5I). 
222 Hindlimb

223 Approximately the distal two thirds of the right tibia and fibula are preserved, with the tibia and fibula in 224 articulation (Fig. 6A-D; Table 1). Using more complete specimens of similar size as a guide (SI 2), we 225 estimate that the tibia in RBCM P900 was likely between 310 and 330 m in length originally. The astragalus and possibly the calcaneum are coossified to the tibia but the boundaries between these elements are difficult to discern. The tibia and astragalus are not coossified in Leptoceratops (CMN 8889; Fig. 6F,G), Cerasinops (MOR 300; Fig. 6H-J) or Montanoceratops (MOR 542) and in these specimens the boundary between these elements is clearly discernible. Makovicky (2010) notes that the astragalus is partly coossified with the tibia in Montanoceratops (AMNH 5465). It is unclear whether this an ontogenetic phenomenon, and if it is phylogenetically significant.

In medial and lateral views (Fig. 6A,D) the tibia of RBCM P900 has a pronounced distal curvature that was not observed in any other leptoceratopsid specimens and which does not seem to represent taphonomic deformation, based on the absence of crushing or fractures on the tibia. In distal view (Fig. $6 \mathrm{~B})$, the lateral and medial malleoli are offset at a distinct angle, giving the distal face of the tibia/astragalus a triangular cross section; RBCM P900 has a more pronounced edge marking the confluence between the malleoli compared to the condition in Leptoceratops (CMN 8889), Cerasinops (MOR 300), or Montanoceratops (MOR 542). The tibia of RBCM P900 is straight-sided in anterior and posterior view and tapers towards the midpoint in anterior or posterior view, similar to the condition in Leptoceratops (CMN 8889; Fig. 6F,G), and Montanoceratops (MOR 542), and unlike the strongly kinked morphology observed in Cerasinops (MOR 300; Fig. 6H-J). The tibia narrows significantly along the shaft and has an oval cross section at its broken proximal end. The fibula is narrow, with an oval cross section.

243 A portion of matrix removed from the anterior side of the distal tibia contains what appear to be the 244 remains of four metatarsals in cross section (Fig. 6E), but little can be said about their morphology 245 without further preparation.

246 RBCM P900 preserves a large number of pedal phalanges: III-2, III-3, and III-4, and IV-2, IV-3, IV-4, and 247 IV-5 (Fig. 7A-C; Table 2). Pedal digit III was preserved in articulation on a piece of matrix (Fig. 7A,B); digit 248 IV includes IV-2 and IV-3 preserved in articulation and IV-4 and IV-5 can be 'snapped' back into 249 articulation based on the presence of some remaining matrix on these elements (Fig. 7C). The non250 ungual phalanges are somewhat longer than wide, but blocky rather than elongate, and ginglymoid, 
251 distinguishing them from similarly-sized small-bodied ornithischians such as Parksosaurus (Fig. 8). The

252 distinctly ginglymoid nature of the interphalangeal joints is distinct from the non-ginglymoid pedal

253 phalangeal joints in Hadrosauridae (e.g., Zheng et al. 2011).

254 In Leptoceratops (CMN 8889, CMN 8887), Cerasinops (MOR 300), and Montanoceratops (MOR 542) the 255 penultimate pedal phalanx of each major digit is markedly shorter in length compared to the preceding 256 phalanx ( $75 \%-90 \%$ the length of the preceding phalanx); in RBCM P900 the penultimate and preceding 257 phalanx on digits III and IV are similar in size, with the penultimate phalanx actually being slightly longer 258 than the preceding phalanx (Table 2, SI 2). Leptoceratops (AMNH 5205; Brown 1914) and Cerasinops 259 (USNM 13863; Gilmore 1939, Chinnery and Horner 2007) are both illustrated with penultimate 260 phalanges subequal in length to the preceding phalanx, but these are both illustrated as line drawings 261 rather than photographs, measurements were not provided by the authors, the digits in AMNH 5205 262 were not part of an articulated pes, and neither of these specimens were measured for this study. As 263 such, it is unclear if the illustrations accurately reflect the actual morphology of the pedal digits in these 264 two specimens. The figured pes of Udanoceratops PIN 4046/11 (Tereschenko 2008) appears to show penultimate phalanges subequal in length to the preceding phalanx in digits II-IV, but measurements were not provided, and no rationale was provided for why this specimen is referred to Udanoceratops rather than Protoceratops. RBCM P900 can, however, be differentiated from Udanoceratops by the morphology of the pedal unguals, if PIN 4046/11 (Tereschenko 2008) is referable to Udanoceratops rather than Protoceratops.

270 The unguals of RBCM P900 are long and narrow, with a gently curved ventral surface (Fig. 7A-C, E), 271 differing from the broad, hoof-shaped unguals of ceratopsids or the wide triangular unguals of 272 protoceratopsids (Sternberg 1951). Their overall shape is similar to the unguals of most other 273 leptoceratopsids, with the possible exception of Udanoceratops based on specimen PIN 4046/11 where 274 the proximal articular surface of the ungual is much wider than the distal articular surface of the 275 penultimate phalanx (Tereschenko 2008). Lateral grooves on the unguals of RBCM P900 are shallow. The 276 unguals of Leptoceratops specimen CMN 8889 have a longitudinal furrow on the ventral surface, but 277 these are absent in the smaller Leptoceratops specimen CMN 8887, and ventral furrows were not 278 observed on any other leptoceratopsid unguals examined for this study. No ventral furrows are present 279 on the unguals of RBCM P900. The unguals of RBCM P900 appear slightly deeper in lateral view 280 compared to other leptoceratopsids, but it is unclear how much this is influenced by taphonomic factors 
281 (e.g. the pedal elements of Cerasinops MOR 300 are severely crushed), ontogeny, or body size (e.g.

282 Montanoceratops MOR 542 is substantially smaller than RBCM P900).

283

284

\section{RESULTS OF THE PHYLOGENETIC ANALYSES}

285

The phylogenetic analysis of the He et al. (2015) modified matrix recovered 7 most parsimonious trees, each with a tree length of 328 , a consistency index of 0.60 , a retention index of 0.80 , and a best tree-bisection reconnection score of 326 (Fig. 8). The strict consensus tree (Fig. 8) is nearly identical to that presented by He et al. (2015), with a basal grade of small-bodied ceratopsians and two derived clades, Coronosauria and Leptoceratopsidae. Within Leptoceratopsidae, the recovered relationships are similar to those found by He et al. (2015), with Asiaceratops and Cerasinops recovered as successive sister taxa to all other leptoceratopsids, Montanoceratops and Ischioceratops as sister taxa, and Prenoceratops as the sister taxon to an unresolved clade of the six remaining leptoceratopsids, including Ferrisaurus. Within this clade, Ferrisaurus has an unresolved relationship with the North American taxa Leptoceratops, Gryphoceratops and Unescoceratops and the Asian taxa Udanoceratops and that could be coded for Ferrisaurus. In two of the seven trees, Ferrisaurus and Udanoceratops were sister taxa; the position of Ferrisaurus differs in the other five trees. Moving Ferrisaurus basally in the tree, outside of Coronosauria+Leptoceratopsidae, increases the tree length to 329, and moving Ferrisaurus into Ceratopsidae increases the tree length to 331.

300 The analysis of the Morschhauser et al. (2019) unmodified matrix recovered 1110 most parsimonious 301 trees, each with a tree length of 694 , a consistency index of 0.45 , a retention index of 0.67 , and a best 302 tree-bisection reconnection score of 688. Morschhauser et al.'s (2019) strict consensus tree shows a 303 poorly resolved sister clade to Coronosauria consisting of taxa typically recovered as leptoceratopsids in 304 other analyses plus Koreaceratops and Helioceratops. The addition of Ferrisaurus to this matrix collapses 305 this clade, and Ferrisaurus is recovered in an unresolved polytomy of leptoceratopsids plus Aquilops, 306 Archaeoceratops, Auroraceratops, Helioceratops, and Koreaceratops, outside of Coronosauria. In 63\% of 307 the trees, Ferrisaurus is recovered as a leptoceratopsid in an unresolved clade consisting of Cerasinops, 308 Ischioceratops, Leptoceratops, Montanoceratops, Prenoceratops, Udanoceratops, Zhuchengceratops, 309 and Gryphoceratops+Unescoceratops, with Helioceratops as the outgroup. 
311 The fact that RBCM P900, the first dinosaur specimen recovered from the Sustut Basin, is a

312 leptoceratopsid rather than one of the more commonly encountered groups in many coeval formations

313 in western North America, such as hadrosaurs, ceratopsids, or tyrannosaurs, is surprising, especially

314 given well-documented preservational biases against small-bodied dinosaurs in more fossiliferous areas

315 (Brown et al. 2013a, b; Evans et al., 2013). Most leptoceratopsid taxa are distinguished on the basis of

316 cranial morphology, especially aspects of the lower jaw anatomy (e.g., Ryan et al. 2012). However,

317 excellent postcranial material is known for many taxa, making it possible to identify diagnostic features

318 in RBCM P900 despite the absence of cranial material for this specimen. Leptoceratops,

319 Montanoceratops, and Cerasinops are all known from multiple partial or complete skeletons (Chinnery

320 and Weishampel 1998, Chinnery and Horner 2007, Ostrom 1978, Brown and Schlaikjer 1942, Sternberg

321 1951, Brown 1914), and Prenoceratops specimens described by Chinnery (2004) come from a single

322 mixed bonebed from which multiple composite skeletons have been assembled.

323 Digit proportions have been used to distinguish caenagnathids (e.g. Zanno and Sampson 2005),

324 oviraptorids (Longrich et al. 2010), and ornithomimids (Kobayashi and Barsbold 2006) at low taxonomic

325 levels, and we show that they can also be used to distinguish among leptoceratopsids. In all specimens

326 preserving partial or complete articulated pedes that we were able to personally observe and measure,

327 the penultimate phalanx (preceding the ungual) for each major digit is shorter in length than the

328 immediately preceding phalanx. In other words, pedal phalanx length decreases distally in the digit,

329 except for the unguals (Fig. 7). In Ferrisaurus, the penultimate phalanx is subequal in length to the

330 preceding phalanx in digits 3 and 4, and phalanx length does not decrease distally within each pedal

331 digit. This appears to be unique to Ferrisaurus within leptoceratopsids with two exceptions. This

332 morphology may be present in a referred specimen of Udanoceratops (PIN 4046/11, Tereschenko 2008,

333 although it is not clear that this specimen is not referable to Protoceratops, and measurements were not

334 provided. Gilmore (1913) published measurements for USNM 13863 (Cerasinops) and noted the length

335 of III-2 as 27.5 and III-3 as $29.5 \mathrm{~mm}$; although we have not had the opportunity to observe this specimen

336 in person, a 2 millimeter length increase between III-2 and III-3 is far outside the range of variation we

337 observed in leptoceratopsids over the course of this study (Table 2, SI 2), but is within the range of

338 variation of a decrease in length between III-2 and III-3. Additionally, phalanges in digit IV show the

339 more typical reduction in length distally. We suggest it is possible that III-2 and III-3 in USNM 13863

340 were at some point transposed in their positions, despite the pes being reported as articulated at the

341 time of collection by Gilmore (1913). Longer penultimate phalanges may also be present in more basal

342 ceratopsian taxa such as Archaeoceratops (You and Dodson 2003), although phalangeal measurements

Peer) reviewing PDF | (2019:06:38350:1:1:NEW 18 Sep 2019) 
343 were not provided in the descriptions of this taxon; phalangeal length decreases in Yinlong as for

344 leptoceratopsids except Ferrisaurus (Han et al. 2018). Overall, the observed pattern for leptoceratopsids

345 appears to be a marked decrease in non-ungual phalangeal length in each pedal digit, with the exception

346 of Ferrisaurus.

347 The astragalus and tibia in RBCM P900 are coossified (Fig. 6), an unusual condition among

348 leptoceratopsids that is otherwise reportedin only one specimen of Montanoceratops (AMNH 5465).

349 Coossification of the astragalus and tibia could indicate advanced skeletal maturity in RBCM P900, but

350 this specimen is smaller than specimens in which the tibia and astragalus remain separate (e.g.

351 Leptoceratops CMN 8889, Montanoceratops AMNH 5205), suggesting that size alone does not explain

352 the differences in coossification patterns in leptoceratopsids. It is unclear what the ontogenetic

353 significance of this coossification represents in Ferrisaurus. Fusion of the ankle (distal tibia and fibula)

354 has been proposed as a diagnostic character of the small bodied thescelosaurid Albertadromeus

355 syntarsus from the Campanian of Alberta (Brown et al. 2013b), and a distinctive feature of some

356 coelophysoids such as "Syntarsus"/?Coelophysis kayentakatae (Rowe 1989), mature derived

357 ceratosaurs, such as Cryolophosaurus (Smith et al. 2007), and mature ankylosaurs (Coombs 1971) and

358 ceratopsids (Sues and Averianov 2009).

359 Ferrisaurus shares with Cerasinops a medially bent distal ulna (originally proposed as a diagnostic

360 character for Cerasinops by Chinnery and Horner 2007), a feature that is also present in Prenoceratops

361 (TCM 2003.1.8). This feature is not present in the Maastrichtian-aged leptoceratopsids

362 Montanoceratops and Leptoceratops, which are closest in geological age to Ferrisaurus. Chinnery and

363 Horner (2007) suggested that the medial deflection of the ulna in Cerasinops, as well as the proportions

364 and histology of the limb elements, may indicate that Cerasinops was primarily bipedal rather than

365 quadrupedal. Although limb proportions are more difficult to determine in Ferrisaurus, if the complete

366 tibia was between 310-330 mm (estimated based on more complete tibiae in Leptoceratops and

367 Montanoceratops, SI 2), then the radius of Ferrisaurus would have been no more than $40-43 \%$ of the

368 length of the tibia. This is less than other comparable leptoceratopsids: the radius is $50 \%$ the length of

369 the tibia in Leptoceratops CMN 8889, 48\% in Leptoceratops AMNH 5205, and 47\% in Leptoceratops CMN

3708888 , and much more than $45 \%$ in the incomplete radii of Cerasinops MOR 300. Ferrisaurus thus may

371 have had a more robust distal ulna (Fig. 5), but a shorter forelimb overall compared to Cerasinops,

372 suggesting that it too may have been at least facultatively bipedal. Alternately, the robusticity of the 
373 ulna may be related to another aspect of its ecology, such as digging, which has been suggested in the

374 orodromine Oryctodromeus (Fearon and Varricchio 2015) and Protoceratops (Longrich 2010).

375 Ferrisaurus was recovered as a leptoceratopsid using the modified He et al. (2015) character matrix, and 376 as a non-coronosaurian neoceratopsian in the Morschhauser et al. (2019) matrix. Although the precise 377 relationships of Ferrisaurus are unresolved using the He et al. (2015) matrix, we found it to be more 378 closely related to Leptoceratops than Montanoceratops (Fig. 8). Despite their stratigraphic and 379 geographic proximity, Leptoceratops and Montanoceratops are not recovered as close relatives in recent 380 phylogenetic analyses in this analysis or by He et al. (2015) and preceding versions of that matrix.

381 Montanoceratops occupies a relatively basal position within Leptoceratopsidae (Makovicky 2010, Ryan 382 et al. 2012, Farke et al. 2014, He et al. 2015), and was found to be the sister taxon to Ischioceratops from 383 Asia by He et al. (2015). Leptoceratops typically occupies a more derived position and has been 384 recovered as the sister taxon to the Asian Udanoceratops (He et al. 2015). Ferrisaurus was thus 385 recovered in a more derived position within Leptoceratopsidae relative to Montanoceratops.

\section{Stratigraphic and palaeobiogeographic implications}

388 Leptoceratopsids are known from the Santonian through Maastrichtian of Laramidia (Ryan et al. 2012), 389 and the Campanian-Maastrichtian of Mongolia and China (He et al. 2015); fragmentary putative leptoceratopsids have also been reported from the Cenomanian of Uzbekistan (Nessov et al. 1989), the ?Coniacian-Santonian of Belgium (Godefroit et al. 2007, Longrich 2016), the Campanian of North Carolina (Longrich 2016), and the Campanian of Sweden (Lindgren et al. 2007). The ancestor of the leptoceratopsid lineage most likely originated in Asia (Chinnery-Allgeier and Kirkland 2010), but multiple exchanges across Beringia from Asia to North America (and vice versa) may have occurred. Gryphoceratops, the oldest taxon, derives from the Deadhorse Coulee Member of the Milk River Formation, with a minimum age of about 83.7 Ma (Ryan et al. 2012). Campanian Laramidian taxa include

397 Cerasinops from the lower Two Medicine Formation, Prenoceratops from the upper Two Medicine Formation of Montana and Oldman Formation of Alberta, and Unescoceratops from the lower Dinosaur Park Formation (Chinnery 2004, Chinnery and Horner 2007, Ryan et al. 2012). Only two genera are known from the Maastrichtian of Laramidia: Montanoceratops from the St Mary River and Horseshoe

401 Canyon formations (Brown and Schlaikjer 1942, Chinnery and Weishampel 1998, Makovicky 2001), and

402 Leptoceratops from the Scollard and Hell Creek formations (Sternberg 1951, Ott 2002) and the Pinyin 
403 Conglomerate (McKenna and Love 1970). RBCM P900 was most likely collected from approximately 68.2 404 to 67.2 Ma sediments of the Tatlatui Member of the Tango Creek Formation, based on a recent field 405 reassessment of its original collection locality and palynomorphs recovered from that site (Arbour et al. 406 in press). This places it between the stratigraphic ranges for Montanoceratops (71.939-68 Ma) and 407 Leptoceratops (66.97 - $66 \mathrm{Ma}$ ), and slightly overlapping with the known range of Montanoceratops 408 (Fowler 2017).

409 Stratigraphically, Montanoceratops and Leptoceratops are the most likely taxa to which RBCM P900 410 could be referred, but multiple anatomical features distinguish RBCM P900 from both Leptoceratops and 411 Montanoceratops, including the proportions of the pedal digits, the proportions of the ulna, and the 412 medially bowed morphology of the distal ulna. RBCM P900 is also unlikely to represent an individual of 413 Cerasinops or Prenoceratops; it can be distinguished from Cerasinops based on the proportions of the 414 pedal digits, and from both Cerasinops and Prenoceratops based on the proportions of the ulna. These 415 morphological differences are reinforced by the stratigraphic position of Ferrisaurus relative to 416 Cerasinops and Prenoceratops (latest Maastrichtian, vs. middle to Upper Campanian; Chinnery and 417 Horner 2007, Chinnery 2004), given that no other dinosaur species with temporally well-resolved 418 specimens spans the middle Campanian to latest Maastrichtian elsewhere in Laramidia (e.g. Eberth et al. 419 2013, Fowler 2017). An enigmatic specimen, TMP 1982.11.1, from the Maastrichtian Willow Creek 420 Formation (Miyashita et al. 2010) has been referred to Montanoceratops by several authors (Ryan and 421 Currie 1998), but was considered neither a representative of Montanoceratops, Leptoceratops, or 422 Cerasinops by Makovicky (2010). Several additional as-yet undescribed specimens in the collections of 423 the TMP (Tanke 2007) may represent examples of either Montanoceratops, Leptoceratops, or 424 Ferrisaurus and their description may help clarify the differences between these three taxa or provide new anatomical information for Ferrisaurus.

Leptoceratopsids are uncommon components of the dinosaurian faunas of Laramidia: even in the well-

427 sampled Dinosaur Park Formation of Alberta only a handful of leptoceratopsid specimens are known.

428 Ryan and Evans (2005) hypothesized that leptoceratopsids may have avoided the wet coastal 429 environments favoured by ceratopsids. Elsewhere in North America, Leptoceratops appears to be 430 present primarily in piedmont and alluvial plain palaeoenvironments and is largely absent in coastal 431 plain settings (Lehman 1987, although see Ott 2007). The Tatlatui Member of the Tango Creek 432 Formation represents an alluvial plain palaeoenvironment (Bustin and McKenzie 1989), consistent with 433 the palaeoenvironmental association documented for other Maastrichtian leptoceratopsids. 
434 Interestingly, the intermontane basin occurrence of Ferrisaurus also supports one hypothesis outlined 435 by Lehman $(1987,2001)$, that leptoceratopsids, along with a few other large-bodied herbivorous taxa, 436 were inhabitants of Cordilleran highlands and adjacent piedmonts, which, in part, explains their rarity in 437 the fossil record.

438 Although today the holotype locality for Ferrisaurus is found at approximately $56^{\circ} \mathrm{N}$ today, the unusual 439 and complex translational history of the Intermontane Superterrane means its palaeolatitude may have 440 lain as much as $1600 \mathrm{~km}$ to the south of its current position with respect to cratonic North America, and 441 may have had approximately the same palaeolatitude $\left(\sim 48^{\circ} \mathrm{N}\right)$ as the southern border of Oregon and 442 Idaho (Enkin et al. 2003, van Hinsbergen et al. 2015). Despite its current apparent northern latitude, the 443 holotype of Ferrisaurus may actually represent one of the southernmost occurrences of

444 Leptoceratopsidae in western North America, and at minimum would have been within the currently 445 known latitudinal range of Laramidian leptoceratopsids. Regardless, RBCM P900 represents a western 446 range extension for Laramidian leptoceratopsids, and a unique occurrence within a restricted 447 intermontane basin palaeoenvironment. The identification of RBCM P900 as a unique leptoceratopsid 448 distinct from other known Laramidian taxa supports previous conclusions by Makovicky (2010) and Ryan 449 et al. (2012) that Leptoceratopsidae was a diverse but currently poorly sampled lineage of Late 450 Cretaceous ceratopsians.

\section{CONCLUSIONS}

RBCM P900, previously identified as an indeterminate bipedal neornithischian by Arbour and Graves

454 (2008), instead represents the partial skeleton of a leptoceratopsid ceratopsian similar in size to large 455 specimens of Leptoceratops and Cerasinops. Although fragmentary, this specimen can be differentiated 456 from other leptoceratopsids based on the proportions and morphology of the ulna and pedal digits, and 457 is designated the holotype of the new taxon Ferrisaurus sustutensis. RBCM P900 was collected from the 458 Sustut Group of the southern Sustut Basin, a large but relatively unexplored terrestrial Cretaceous basin 459 in northern British Columbia, Canada. Its recognition as a distinct species of a generally rare group of 460 small-bodied dinosaurs highlights the potential for future discoveries of unique dinosaur biodiversity 461 within the intermontane basins of the western side of the North American Cordillera. 


\section{Supplementary Information}

464 SI 1 - Specimens examined and character statements, .docx

465 SI 2 - Comparative measurements, .csv

466 SI 3 - Photogrammetric digital models of RBCM P900 are available at Morphosource: coracoid -

467 https://doi.org/10.17602/M2/M81919, https://doi.org/10.17602/M2/M86250; scapula -

468 https://doi.org/10.17602/M2/M82514, https://doi.org/10.17602/M2/M86251; radius -

469 https://doi.org/10.17602/M2/M81854, https://doi.org/10.17602/M2/M86248; ulna -

470 https://doi.org/10.17602/M2/M81857, https://doi.org/10.17602/M2/M86249; tibia/fibula -

471 https://doi.org/10.17602/M2/M81513, https://doi.org/10.17602/M2/M86245; metatarsals -

472 https://doi.org/10.17602/M2/M86252, https://doi.org/10.17602/M2/M86253; pedal digit III -

473 https://doi.org/10.17602/M2/M81852, https://doi.org/10.17602/M2/M86246; pedal digit IV-4 -

474 https://doi.org/10.17602/M2/M86254, https://doi.org/10.17602/M2/M86255

475 SI 4-Character-taxon matrix modified from H et al. (2015), .nex

476 SI 5 - Character-taxon matrix modified from Morschhauser et al. (2019), .nex

477

\section{ACKNOWLEDGEMENTS}

479 The RBCM P900 field locality is located on the unceded traditional territory of the Gitxsan peoples. MOR

480300 was collected from the Wilson Hodgkiss Ranch, and MOR 542 was collected from private land 481 deeded from the Blackfeet Nation. Many thanks to D. Evans (Children's Museum of Indianapolis), Jordan 482 Mallon and Kieran Shepherd (Canadian Museum of Nature), Amy Atwater, Scott Williams, and John 483 Scannella (Museum of the Rockies), Brandon Strilisky and Caleb Brown (Royal Tyrrell Museum of 484 Palaeontology), and Carl Mehling (American Museum of Nature History) for access to specimens in their 485 collections. Peter Makovicky shared photographs of Udanoceratops, Kentaro Chiba, Cary Woodruff and 486 Bobby Boessenecker provided assistance with digital modelling and photogrammetry, and Derek Larson 487 provided assistance with Latinization of the genus name. Funding for this project was provided by an 488 NSERC postdoctoral fellowship, an NSERC L'Oréal-UNESCO for Women in Science fellowship 489 supplement, a National Geographic Society Waitt Grant, and a Dinosaur Research Institute grant to 
490 VMA, and an NSERC Discovery Grant to DCE. Many thanks to editor Hans-Dieter Sues and reviewers

491 Andy Farke and Brenda Chinnery for constructive comments that improved the manuscript.

492

493

LITERATURE CITED

494

Arbour VM, Evans DC, Simon DJ, Cullen TM, Braman D. In press. Cretaceous flora and fauna of the Sustut 495 Group near the Sustut River, northern British Columbia, Canada. Canadian Journal of Earth Sciences.

496

Arbour VM, Graves MC. 2008. An ornithischian dinosaur from the Sustut Basin, north-central British

497 Columbia, Canada. Canadian Journal of Earth Sciences 45:457-463.

498

Brown B. 1914. Leptoceratops, a new genus of Ceratopsia from the Edmonton Cretaceous of Alberta. Bulletin of the American Museum of Natural History 33:567-580.

500 Brown B, Schlaikjer EM. 1942. The skeleton of Leptoceratops with the description of a new species.

501 American Museum Novitates 1169:1-15.

502 Brown CM, Evans DC, Campione NE, O'Brien LJ, Eberth DA. 2013a. Evidence for taphonomic size bias in 503 the Dinosaur Park Formation (Campanian, Alberta), a model Mesozoic terrestrial alluvial-paralic system.

504 Palaeogeography, Palaeoclimatology, Palaeoecology 372:108-122.

505 Brown CM, Evans DC, Ryan MJ, Russell AP. 2013b. New data on the diversity and abundance of small506 bodied ornithopods (Dinosauria, Ornithischia) from the Belly River Group (Campanian) of Alberta.

507 Journal of Vertebrate Paleontology 33 (3): 495

508 Bustin RM, McKenzie KJ. 1989. Stratigraphy and depositional environments of the Sustut Group, 509 southern Sustut Basin, north central British Columbia. Bulletin of Canadian Petroleum Geology 37: 210510223

511 Chinnery B. 2004. Description of Prenoceratops pieganensis gen. et sp. nov. (Dinosauria: Neoceratopsia)

512 from the Two Medicine Formation of Montana. Journal of Vertebrate Paleontology 24:572-590.

513 Chinnery BJ, Weishampel DB. 1998. Montanoceratops cerorhynchus (Dinosauria: Ceratopsia) and

514 relationships among basal neoceratopsians. Journal of Vertebrate Paleontology 18:569-585. 
515 Chinnery BJ, Horner JR. 2007. A new neoceratopsian dinosaur linking North American and Asian taxa.

516 Journal of Vertebrate Paleontology 27:625-641.

517 Chinnery-Allgeier BJ, Kirkland JI. 2010. An update on the paleobiogeography of ceratopsian dinosaurs.

518 In: Ryan MJ, Chinnery-Allgeier BJ, Eberth DA (eds) New perspectives on horned dinosaurs. Indiana

519 University Press, p. 387-404.

520 Coombs W. 1971. The Ankylosauridae. PhD thesis, Columbia University, New York, 487 p.

521 Currie PJ, Holmes RB, Ryan MJ, Coy C. 2016. A juvenile chasmosaurine ceratopsid (Dinosauria,

522 Ornithischia) from the Dinosaur Park Formation, Alberta, Canada. Journal of Vertebrate Paleontology 26: 523 e1048348.

524 Eberth DA, Evans DC, Brinkman DB, Therrien F, Tanke DH, Russell LS. 2013. Dinosaur biostratigraphy of 525 the Edmonton Group (Upper Cretaceous), Alberta, Canada: evidence for climate influence. Canadian 526 Journal of Earth Sciences 50:701-726.

527 Enkin RJ, Mahoney JB, Baker J, Riesterer J, and Haskin ML. 2003. Deciphering shallow paleomagnetic 528 inclinations: 2. Implications from Late Cretaceous strata overlapping the Insular/Intermontane 529 Superterrane boundary in the southern Canadian Cordillera. Journal of Geophysical Research 108:1-19.

530 Evenchick CA, Ferri F, Mustard PS, McMechan M, Osadetz KG, Stasiuk L, Wilson NSF, Enkin RJ, Hadlari T, 531 and McNicoll VJ. 2003. Recent results and activities of the Integrated Petroleum Resource Potential and 532 Geoscience Studies of the Bowser and Sustut Basins project, British Columbia. Current Research, 533 Geological Survey of Canada 2003-A13:1-11.

534 Evans DC, Schott RK, Larson DW, Brown CM, Ryan MJ. 2013. The oldest North American 535 pachycephalosaurid and the hidden diversity of small-bodied ornithischian dinosaurs. Nature 536 Communications 4: 1-10.

537 Farke AA, Maxwell WD, Cifelli RL, Wedel MJ. 2014. A ceratopsian dinosaur from the Lower Cretaceous of 538 western North America, and the biogeography of Neoceratopsia. PLOS ONE 9:e112055.

539 Fearon JL, Varricchio DJ. 2015. Morphometric analysis of the forelimb and pectoral girdle of the

540 Cretaceous ornithopod dinosaur Oryctodromeus cubicularis and implications for digging. Journal of 541 Vertebrate Paleontology 35. 
542 Fowler DW. 2017. Revised geochronology, correlation, and dinosaur stratigraphic ranges of the

543 Santonian-Maastrichtian (Late Cretaceous) formations of the Western Interior of North America. PLoS

544 ONE 12:e0188426.

545 Godefroit P, Lambert O. 2007. A re-appraisal of Craspedodon lonzeensis Dollo, 1883 from the Upper

546 Cretaceous of Belgium: the first record of a neoceratopsian dinosaur in Europe? Bulletin de l'Institut

547 Royal des sciences naturelles de Belgique, sciences de la terre 77:83-93.

548 Goloboff PA, Farris JS, Nixon KC. 2008. TNT, a free program for phylogenetic analysis. Cladistics 24:774-

549786.

550 Gilmore CW. 1939. Ceratopsian dinosaurs from the Two Medicine Formation, Upper Cretaceous of

551 Montana. Proceedings of the United States National Museum 87:1-18.

552 Han F, Forster CA, Xu X, Clark JM. 2018. Postcranial anatomy of Yinlong downsi (Dinosauria: Ceratopsia)

553 from the Upper Jurassic Shishugou Formation of China and the phylogeny of basal ornithischians.

554 Journal of Systematic Palaeontology 16: 1159-1187.

555 ]He Y, Makovicky PJ, Wang K, Chen S, Sullivan C, Han F, Xu X. 2015. A new leptoceratopsid (Ornithischia,

556 Ceratopsia) with a unique ischium from the Upper Cretaceous of Shandong Province, China. PLOS ONE

$557 \quad 10: \mathrm{e} 0144148$.

558 Kobayashi Y, Barsbold R. 2006. Ornithomimids from the Nemegt Formation of Mongolia. J Paleont Soc

559 Korea 22:195-207.

560 Lehman TM. 1987. Late Maastrichtian paleoenvironments and dinosaur biogeography in the western

561 interior of North America. Palaeogeography, Palaeoclimatology, Palaeoecology 60:189-217.

562 Lehman TM. 2001. Late Cretaceous dinosaur provinciality. In Tanke DH, Carpenter K (eds) Mesozoic

563 vertebrate life: new research inspired by the paleontology of Philip J. Currie. Indiana University Press,

564 pp 310-328.

565 Lindgren J, Currie PJ, Siverson M, Rees J, Cederström P, Lindgren F. 2007. The first neoceratopsian

566 dinosaur remains from Europe. Palaeontology 50:929-937. 
567 Longrich N. 2010. The function of large eyes in Protoceratops: a nocturnal ceratopsian? In: Ryan MJ,

568 Chinnery-Allgeier BJ, Eberth DA (eds) New Perspectives on Horned Dinosaurs: The Royal Tyrrell Museum 569 Ceratopsian Symposium. Indiana University Press, pp. 308-327.

570 Longrich NR. 2016. A ceratopsian dinosaur from the Late Cretaceous of eastern North America, and 571 implications for dinosaur biogeography. Cretaceous Research 57:199-207.

572 Longrich NR, Currie PJ, Zhi-Ming D. 2010. A new oviraptorid (Dinosauria: Theropoda) from the Upper 573 Cretaceous of Bayan Mandahu, Inner Mongolia. Palaeontology 53:945-960.

574 Maddison WP, Maddison DR. 2011. Mesquite: a modular system for evolutionary analysis. Version 3.04 575 http://mesquiteproject.org

576 Makovicky PJ. 2001. A Montanoceratops cerorhynchus (Dinosauria: Ceratopsia) braincase from the 577 Horseshoe Canyon Formation of Alberta. In: Tanke DH, Carpenter K, Skrepnick MW (eds) Mesozoic 578 Vertebrate Life. Indiana University Press, pp. 243-262.

579 Makovicky PJ. 2010. A redescription of the Montanoceratops cerorhynchus holotype, with a review of 580 referred material. In: Ryan MJ, Chinnery-Allgeier BJ, Eberth DA (eds). New perspectives on horned 581 dinosaurs. Indiana University Press, pp. 68-82.

582 Miyashita TE, Currie PJ, Chinnery-Allgeier BJ. 2010. First basal neoceratopsian from the Oldman 583 Formation (Belly River Group), southern Alberta. In: Ryan MJ, Chinnery-Allgeier BJ, Eberth DA (eds) New 584 perspectives on horned dinosaurs: the Royal Tyrrell Museum Ceratopsian Symposium. Indiana University 585 Press, Bloomington, IN, pp. 83-90.

586 Morschhauser EM, You H, Li D, Dodson P. 2019. Phylogenetic history of Auroraceratops rugosus 587 (Ceratopsia: Ornithischia) from the Lower Cretaceous of Gansu Province, China. Journal of Vertebrate 588 Paleontology 38, suppl 1:117-147.

589 Nessov LA, Kaznyshkina LF, Cherepanov GO. 1989. Ceratopsian dinosaurs and crocodiles of the Mesozoic 590 of Middle Asia In: Bogdanova TN, Khozatsky LI (eds) Theoretical and applied aspects of modern

591 Palaeontology. Leningrad: Nauka, pp. 144-154.

592 Ostrom JH. 1978. Leptoceratops gracilis from the "Lance" Formation of Wyoming. Journal of 593 Paleontology 52: 697-704. 
594 Ott CJ. 2006. Cranial anatomy and biogeography of the first Leptoceratops gracilis (Dinosauria:

595 Ornithischia) specimens from the Hell Creek Formation, southeast Montana. In: Carpenter K (ed). Horns 596 and beaks. Indiana University Press, pp. 213-233.

597 Rowe T. 1989. A new species of the theropod dinosaur Syntarsus from the Early Jurassic Kayenta 598 Formation of Arizona. Journal of Vertebrate Paleontology 9:125-136

599 Ryan MJ, Evans DC. 2005. Ornithischian dinosaurs. In: Currie PJ, Koppelhus EB (eds) Dinosaur Provincial 600 Park: a spectacular ancient ecosystem revealed. Indiana University Press, pp. 312-348.

601 Ryan MJ, Currie PJ. 1998. First report of protoceratopsians (Neoceratopsia) from the Late Cretaceous 602 Judith River Group, Alberta, Canada. Canadian Journal of Earth Sciences 35:820-826.

603 Ryan MJ, Evans DC, Currie PJ, Brown CM, Brinkman D. 2012. New leptoceratopsids from the Upper 604 Cretaceous of Alberta, Canada. Cretaceous Research 35:69-80.

605 Smith ND, Makovicky PJ, Hammer WR, Currie PJ. 2007. Osteology of Cryolophosaurus ellioti (Dinosauria:

606 Theropoda) from the Early Jurassic of Antarctica and implications for early theropod evolution.

607 Zoological Journal of the Linnean Society 151:377-421..

608 Sternberg CM. 1951. Complete skeleton of Leptoceratops gracilis Brown from the Upper Edmonton 609 Member on Red Deer River, Alberta. National Museum of Canada Bulletin, Annual Report 123:225-255.

610 Sues H-D, Averianov A. 2009. Turanoceratops tardabilis - the first ceratopsid dinosaur from Asia.

611 Naturwissenschaften 96:645-652.

612 Tanke DH. 2007. Ceratopsian discoveries and work in Alberta, Canada: Historical review and census. In

613 Braman DR, comp., Ceratopsian Symposium: Short Papers, Abstracts, and Programs. CD ROM appendix. 614 Drumheller: Royal Tyrrell Museum of Palaeontology.

615 Tereschenko VS. 2008. Adaptive features of protoceratopoids (Ornithischia: Neoceratopsia).

616 Paleontological Journal 42:273-286.

617 van Hinsbergen DJJ, de Groot LV, van Schaik SJ, Spakman W, Bijl PK, Sluijs A, Langereis CG, Brinkuis H. 618 2015. A paleolatitude calculator for paleoclimate studies. PLOS ONE 10:e0126946.

619 Xu X, Forster CA, Clark JM, Mo J. 2006. A basal ceratopsian with transitional features from the Late 620 Jurassic of northwestern China. Proceedings of the Royal Society B 273:2135-2140. 
621 You H-L, Tanoue K, Dodson P. A new species of Archaeoceratops (Dinosauria: Neoceratopsia) from the 622 Early Cretaceous of the Mazongshan area, northwestern China. New Perspectives on Horned Dinosaurs.

623 You H.-L., Dodson P. 2003. Redescription of neoceratopsian dinosaur Archaeoceratops and early

624 evolution of Neoceratopsia. Acta Palaeontologica Polonica 48 (2): 261-272.

625 Zanno LE, Sampson SD. 2005. A new oviraptorosaur (Theropoda, Maniraptora) from the Late Cretaceous 626 (Campanian) of Utah. Journal of Vertebrate Paleontology 25:897-904.

627 Zheng R, Farke A, Kim G. 2011. A photographic atlas of the pes from a hadrosaurine hadrosaurid 628 dinosaur. PalArch's Journal of Vertebrate Palaeontology 8: 1-12

629

630

631

632

633

634

635

636

637

638

639

640

641

642

643 


\section{FIGURES}

645 Figure 1: RBCM P900, the holotype of Ferrisaurus sustutensis, was collected along the BC Rail line near

646 the intersection of Birdflat Creek and the Sustut River in 1971, in the Sustut Basin of northern British

647 Columbia, Canada. Map modified from Evenchick et al. (2003).

648 Figure 2: Preserved elements of RBCM P900, holotype of Ferrisaurus sustutensis, in white (grey

649 represents missing parts of incomplete bones). RBCM P900 includes a partial right coracoid, partial left 650 scapular blade, complete left radius, partial left ulna, partial left tibia, fibula, and coossified astragalus

651 and ?calcaneum, partial left metatarsals I-IV, and digits III (phalanges 2-4) and IV (phalanges 2-5) of the 652 right pes.

653 Figure 3: Pectoral elements of RBCM P900, holotype of Ferrisaurus sustutensis, compared to other

654 Laramidian leptoceratopsids. A) Fragmentary right coracoid of RBCM P900 in lateral view, compared to

655 B) complete right scapulocoracoid of CMN 8889, Leptoceratops gracilis, lateral view centered on 656 coracoid with scapula in oblique view. Fragmentary left scapular blade of RBCM P900 in C) lateral and D) 657 medial view, compared to E) left scapula of MOR 300, Cerasinops hodgskissi in medial view, and F) left 658 scapula of TCM 2003.1.9, Prenoceratops pieganensis in lateral view. Abbreviations: sp - sternal process.

659 Figure 4. Radius of RBCM P900, holotype of Ferrisaurus sustutensis, compared to other Laramidian 660 leptoceratopsids. RBCM P900, Ferrisaurus sustutensis, left radius in A) lateral, B) medial, C) proximal, 661 and D) distal view. E) CMN 8889, Leptoceratops gracilis, left radius in lateral view. F) MOR 300, 662 Cerasinops hodgskissi, ?left radius in ?lateral view. Abbreviations: tb - tubercle.

663 Figure 5: Ulna of RBCM P900, holotype of Ferrisaurus sustutensis, compared to other Laramidian 664 leptoceratopsids. RBCM P900, Ferrisaurus sustutensis, left ulna in A) medial and B) distal view. C) CMN 8889 , Leptoceratops gracilis, left ulna in medial view. D) MOR 300, Cerasinops hodgskissi, right ulna in medial view. E) TCM 2003.1.8, Prenoceratops pieganensis, right ulna in medial view. F) MOR 452, Montanoceratops cerorhynchus, right ulna in medial view. G) RBCM P900, Ferrisaurus left ulna in posterior view; arrow indicates medial bend to distal ulna. H) TCM 2003.1.8, Prenoceratops right ulna in anterior view. I) MOR 452, Montanoceratops right ulna in anterior view.

670 Figure 6: Tibia of RBCM P900, holotype of Ferrisaurus sustutensis, compared to other Laramidian 671 leptoceratopsids. RBCM P900, Ferrisaurus left tibia in A) medial, B) and C) posterior, D) anterior, and E) 672 lateral views, and F and G) block removed from anterior face of tibia containing four partial metatarsals. 
673 The dashed line in C) delineates the possible boundary of the astragalus/calcaneum on the tibia, and the

674 dashed lines in E) indicate the preserved metatarsals in cross-section. CMN 8889, Leptoceratops gracilis

675 left tibia in H) posterior and I) anterior view. MOR 300, Cerasinops hodgskissi right tibia in J) anterior and

676 K) posterior views, and L) left tibia in posterior view. Abbreviations: as - astraglus, ca - calcaneum, fib -

677 fibula, ma - matrix, mt - metatarsal.

678 Figure 7: Pedal elements of RBCM P900, holotype of Ferrisaurus sustutensis, compared to other

679 Laramidian small-bodied ornithischians. RBCM P900, Ferrisaurus, left digit III in A) medial and B) lateral

680 views, and C) left digit IV in lateral view. D) MOR 542, Montanoceratops cerorhynchus, right digit IV in

681 lateral view. Illustrations of E) RBCM P900, Ferrisaurus, F) CMN 8889, Leptoceratops gracilis, G) MOR

682 300, Cerasinops hodgskissi, H) MOR 542, Montanoceratops cerorhynchus, in dorsal view, and I) ROM

683 804, Parksosaurus warreni.

684 Figure 8: Results of the phylogenetic analyses showing the relationships of Ferrisaurus sustutensis within

685 Ceratopsia. A) Strict consensus tree using the matrix modified from He et al. (2015). B) Strict consensus

686 tree using the matrix from Morschhauser et al. (2019). 
Figure 1

RBCM P900, the holotype of Ferrisaurus sustutensis, was collected along the BC Rail line near the intersection of Birdflat Creek and the Sustut River in 1971, in the Sustut Basin of northern British Columbia, Canada.

Map modified from Evenchick et al. (2003).

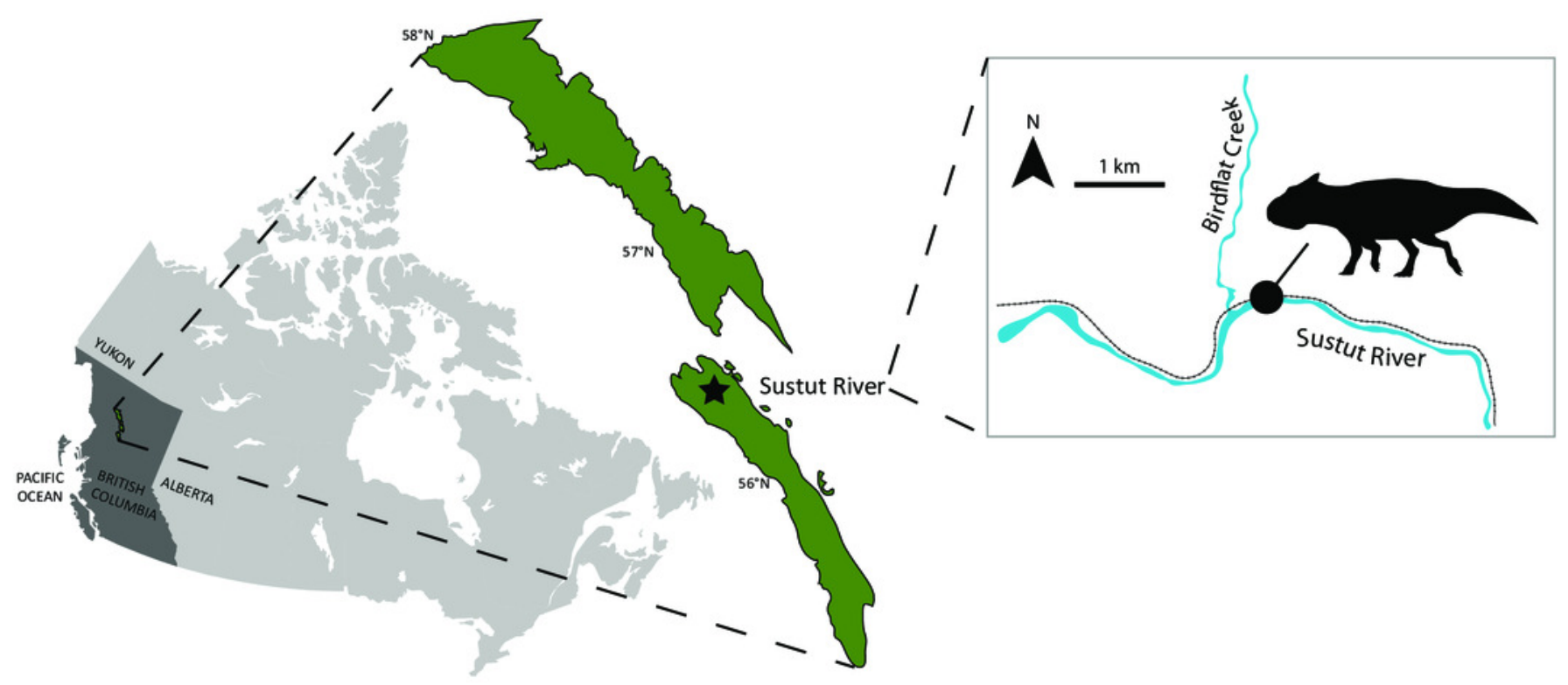




\section{Figure 2}

Preserved elements of RBCM P900, holotype of Ferrisaurus sustutensis, in white (grey represents missing parts of incomplete bones).

RBCM P900 includes a partial right coracoid, partial left scapular blade, complete left radius, partial left ulna, partial left tibia, fibula, and coossified astragalus and ?calcaneum, partial left metatarsals I-IV, and digits III (phalanges 2-4) and IV (phalanges 2-5) of the right pes.

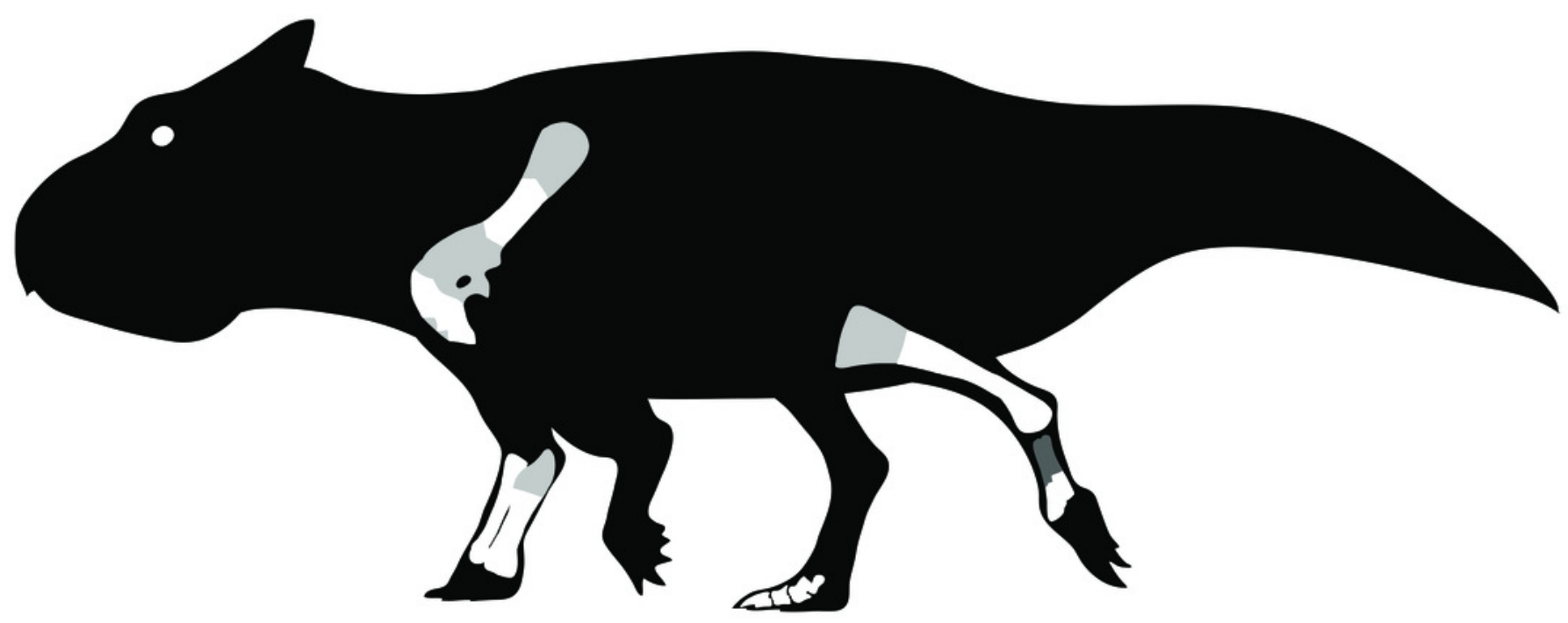




\section{Figure 3}

Pectoral elements of RBCM P900, holotype of Ferrisaurus sustutensis, compared to other Laramidian leptoceratopsids.

A) Fragmentary right coracoid of RBCM P900 in lateral view, compared to B) complete right scapulocoracoid of CMN 8889, Leptoceratops gracilis, lateral view centered on coracoid with scapula in oblique view. Fragmentary left scapular blade of RBCM P900 in C) lateral and D) medial view, compared to E) left scapula of MOR 300, Cerasinops hodgskissi in medial view, and F) left scapula of TCM 2003.1.9, Prenoceratops pieganensis in lateral view.

Abbreviations: $s p$ - sternal process. 


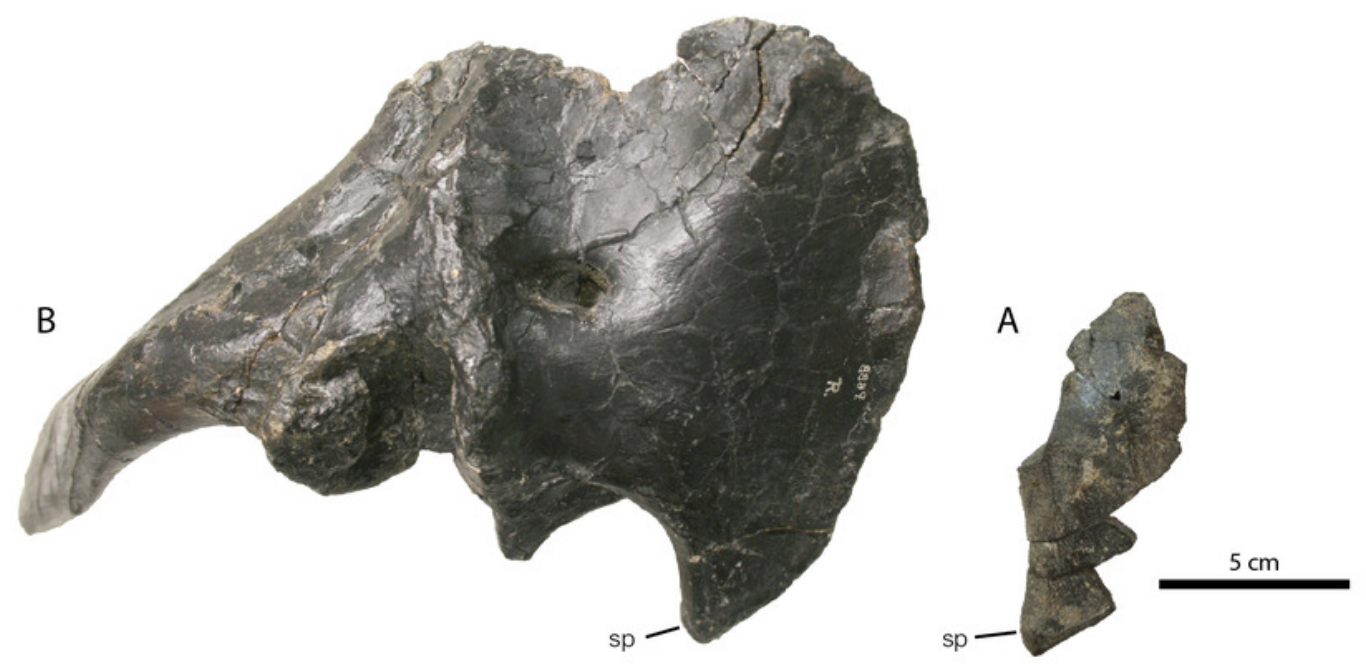

C

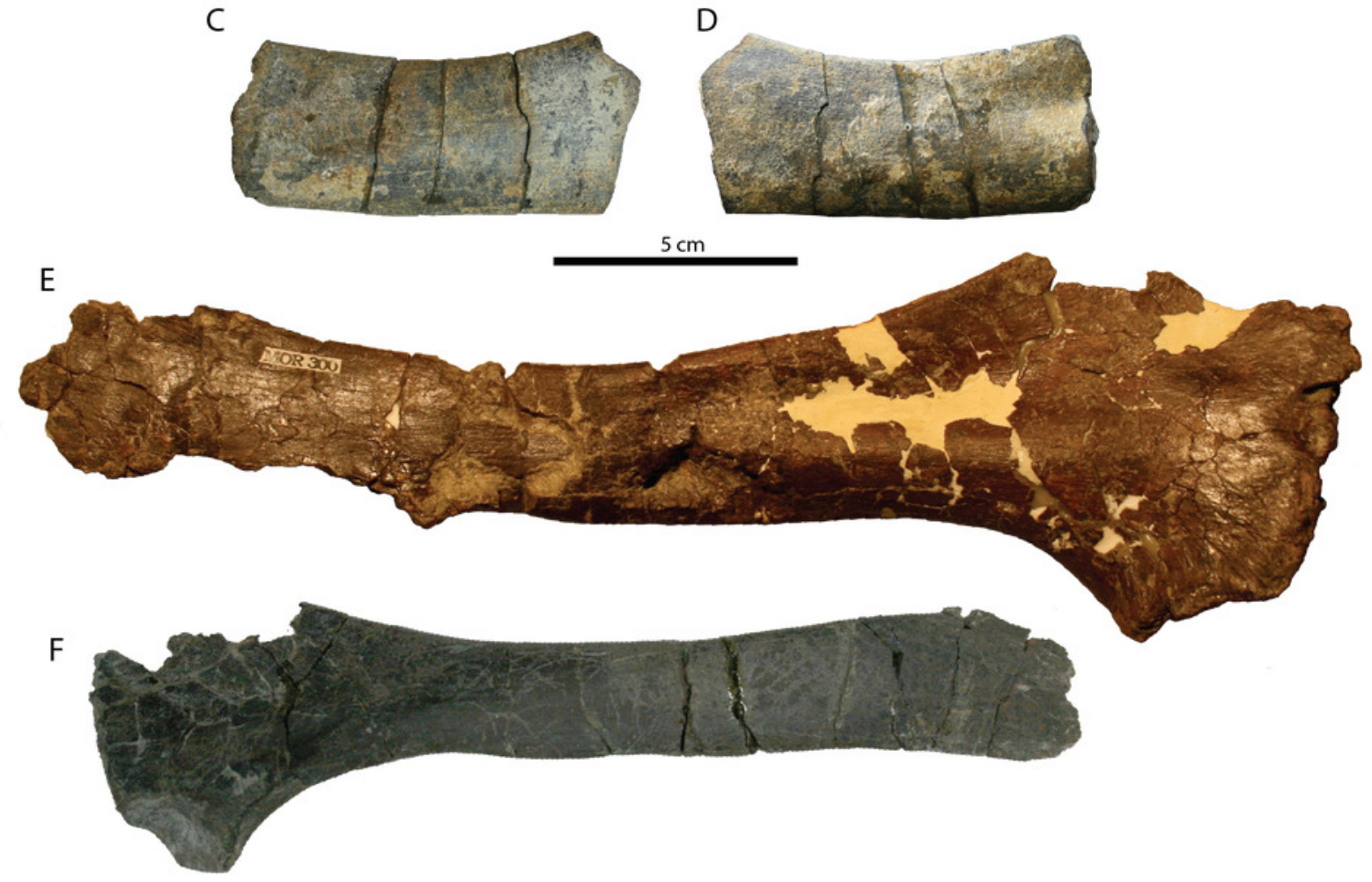

D 
Figure 4

Radius of RBCM P900, holotype of Ferrisaurus sustutensis, compared to other Laramidian leptoceratopsids.

RBCM P900, Ferrisaurus sustutensis, left radius in A) lateral, B) medial, C) proximal, and D) distal view. E) CMN 8889, Leptoceratops gracilis, left radius in lateral view. F) MOR 300, Cerasinops hodgskissi, ?left radius in ?lateral view. Abbreviations: tb - tubercle. 

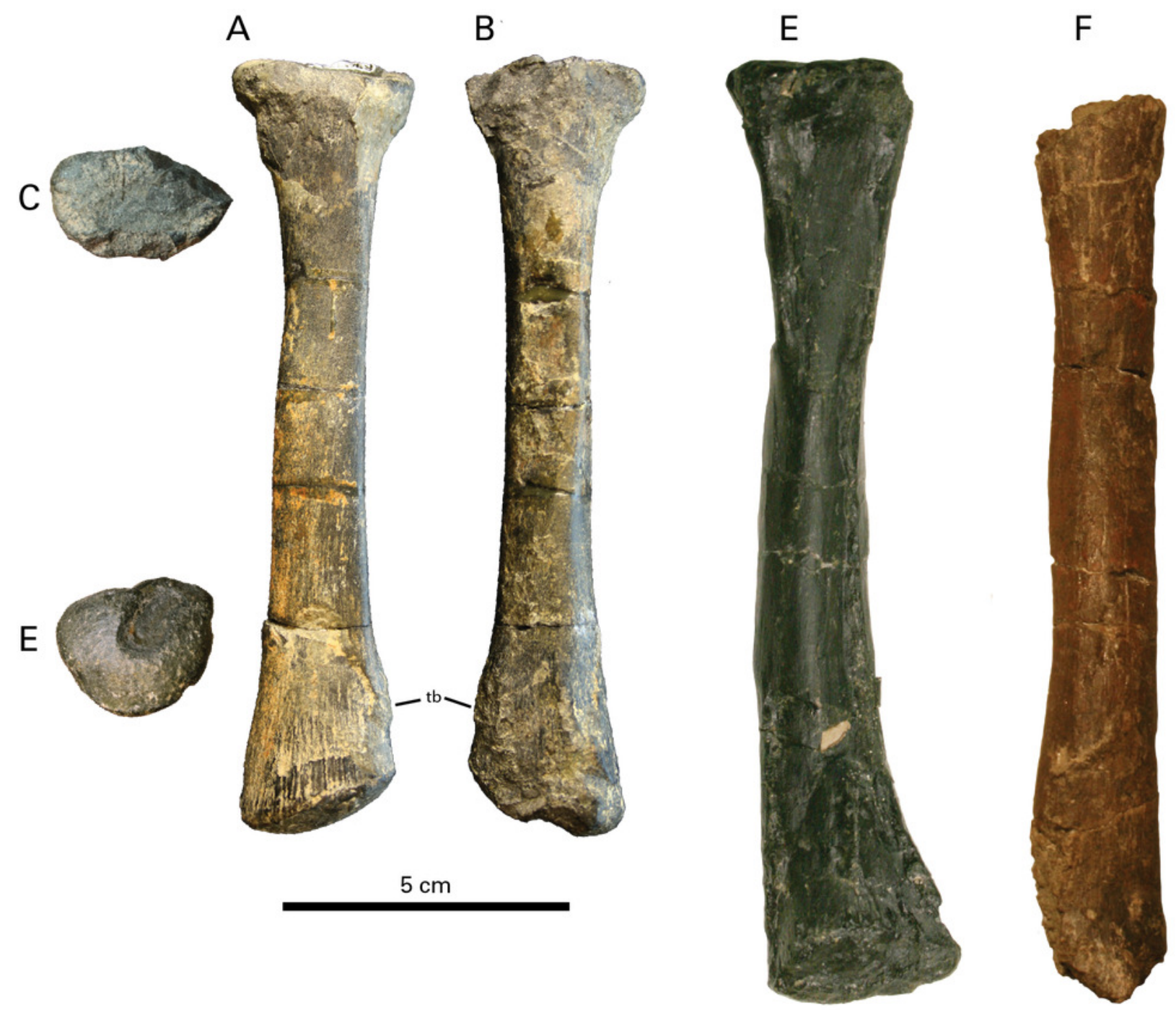


\section{Figure 5}

Ulna of RBCM P900, holotype of Ferrisaurus sustutensis, compared to other Laramidian leptoceratopsids.

RBCM P900, Ferrisaurus sustutensis, left ulna in A) medial and B) distal view. C) CMN 8889, Leptoceratops gracilis, left ulna in medial view. D) MOR 300, Cerasinops hodgskissi, right ulna in medial view. E) TCM 2003.1.8, Prenoceratops pieganensis, right ulna in medial view. F) MOR 452, Montanoceratops cerorhynchus, right ulna in medial view. G) RBCM P900, Ferrisaurus left ulna in posterior view; arrow indicates medial bend to distal ulna. H) TCM 2003.1.8, Prenoceratops right ulna in anterior view. I) MOR 452, Montanoceratops right ulna in anterior view.

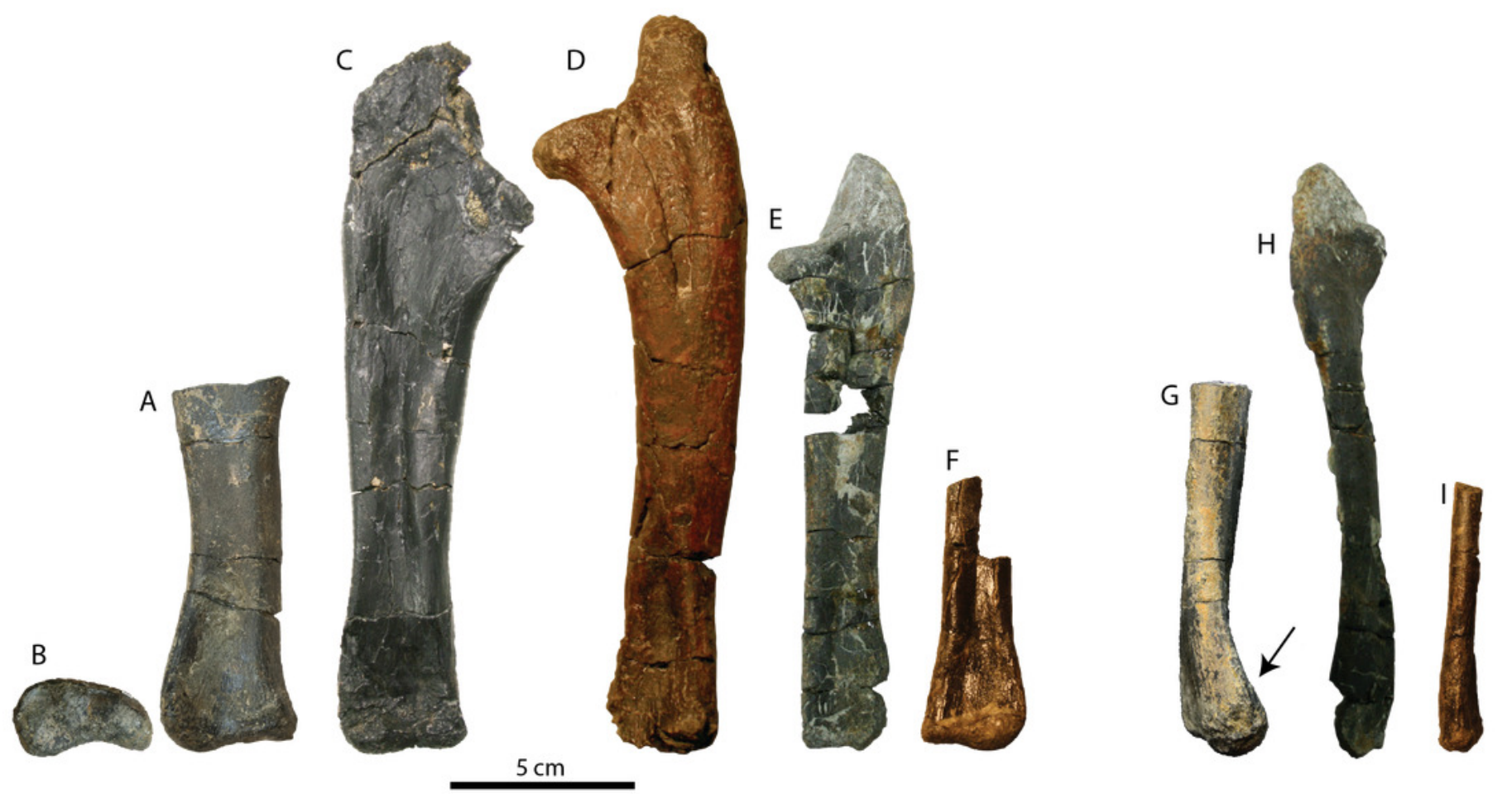




\section{Figure 6}

Tibia of RBCM P900, holotype of Ferrisaurus sustutensis, compared to other Laramidian leptoceratopsids.

RBCM P900, Ferrisaurus left tibia in A) medial, B) and C) posterior, D) anterior, and E) lateral views, and $\mathrm{F}$ and $\mathrm{G}$ ) block removed from anterior face of tibia containing four partial metatarsals. The dashed line in $\mathrm{C}$ ) delineates the possible boundary of the astragalus/calcaneum on the tibia, and the dashed lines in $\mathrm{E}$ ) indicate the preserved metatarsals in cross-section. CMN 8889, Leptoceratops gracilis left tibia in H) posterior and I) anterior view. MOR 300, Cerasinops hodgskissi right tibia in J) anterior and K) posterior views, and L) left tibia in posterior view. Abbreviations: as - astraglus, ca - calcaneum, fib - fibula, ma - matrix, mt - metatarsal. 


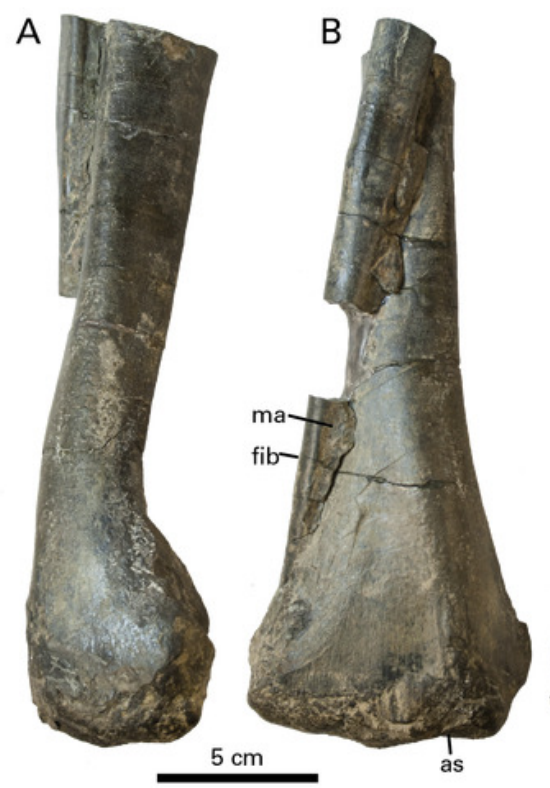

$\mathrm{H}$

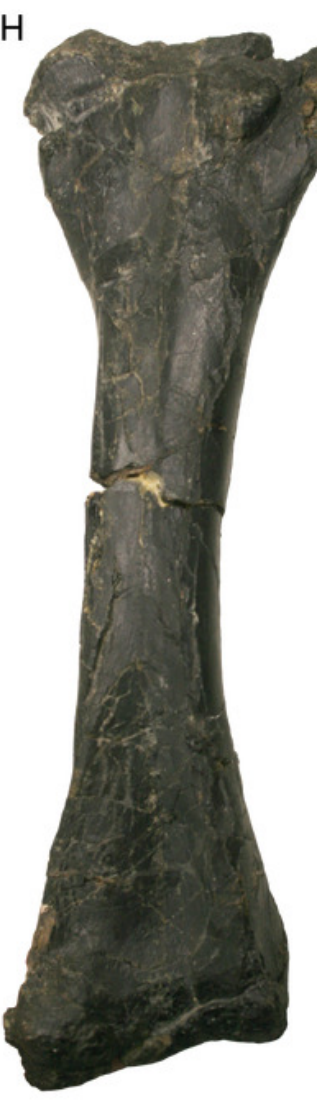

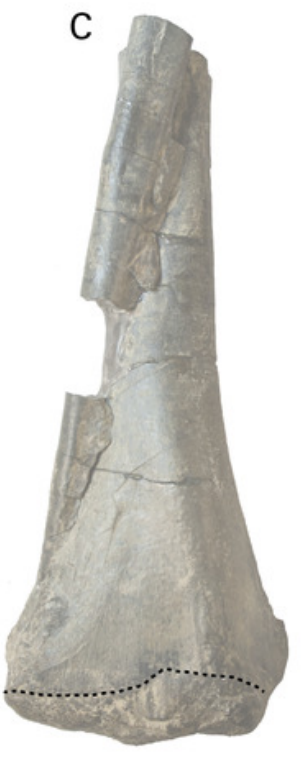

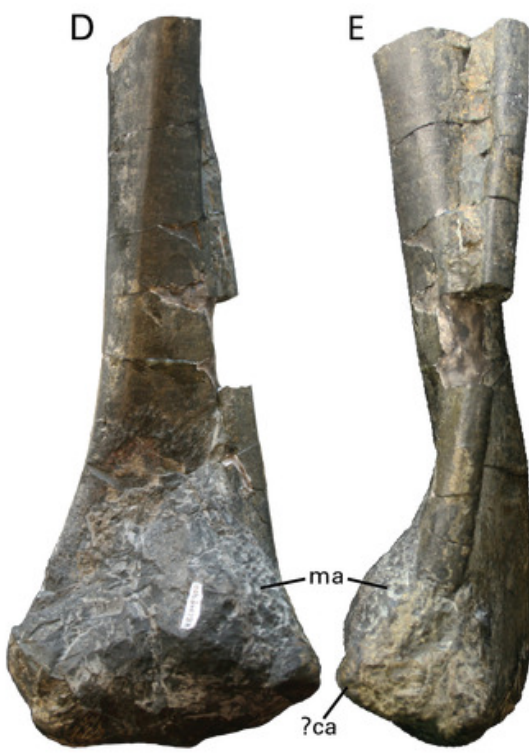

K

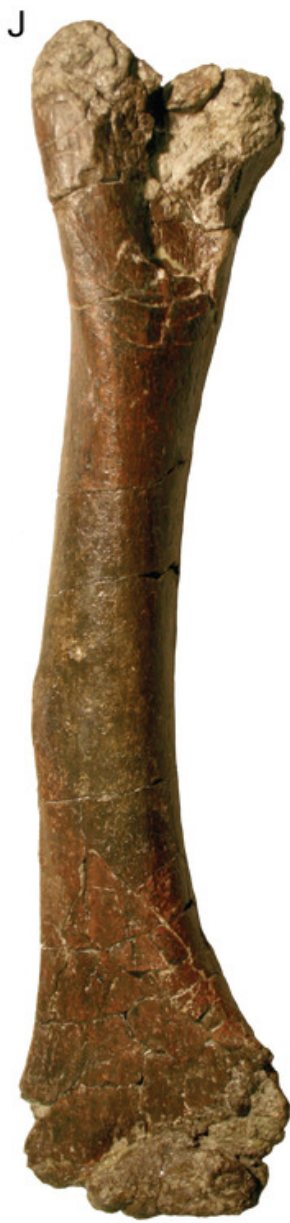

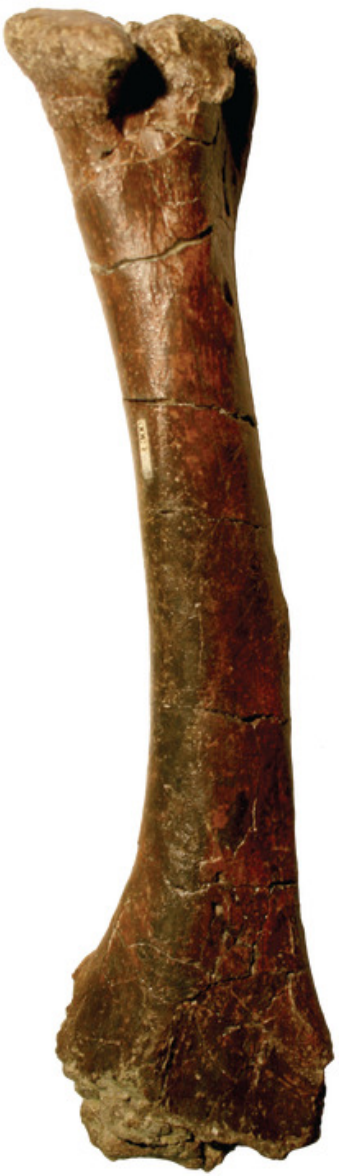

$\mathrm{F}$
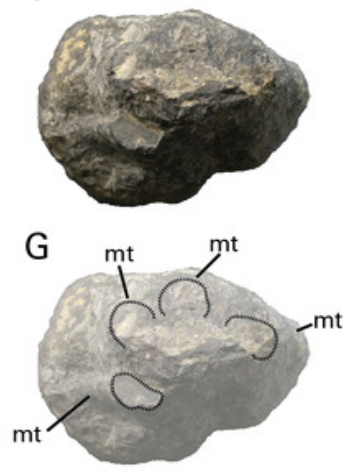

$\mathrm{L}$

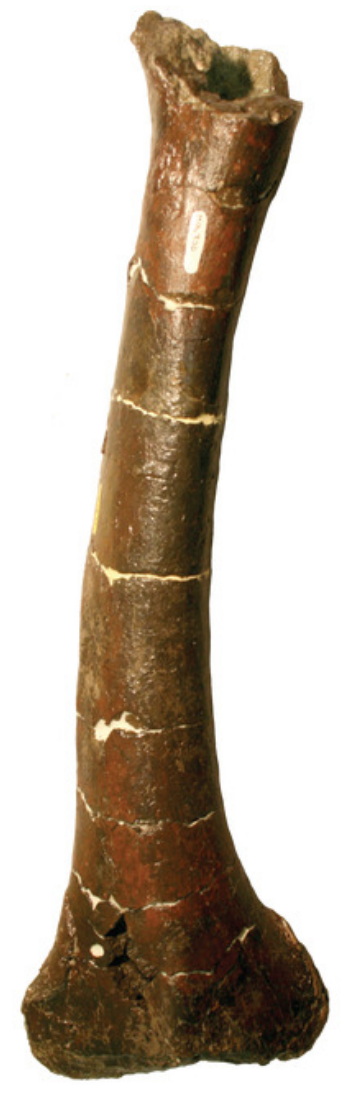




\section{Figure 7}

Pedal elements of RBCM P900, holotype of Ferrisaurus sustutensis, compared to other Laramidian small-bodied ornithischians.

RBCM P900, Ferrisaurus, left digit III in A) medial and B) lateral views, and C) left digit IV in lateral view. D) MOR 542, Montanoceratops cerorhynchus, right digit IV in lateral view.

Illustrations of E) RBCM P900, Ferrisaurus, F) CMN 8889, Leptoceratops gracilis, G) MOR 300, Cerasinops hodgskissi, H) MOR 542, Montanoceratops cerorhynchus, in dorsal view, and I) ROM 804, Parksosaurus warreni.
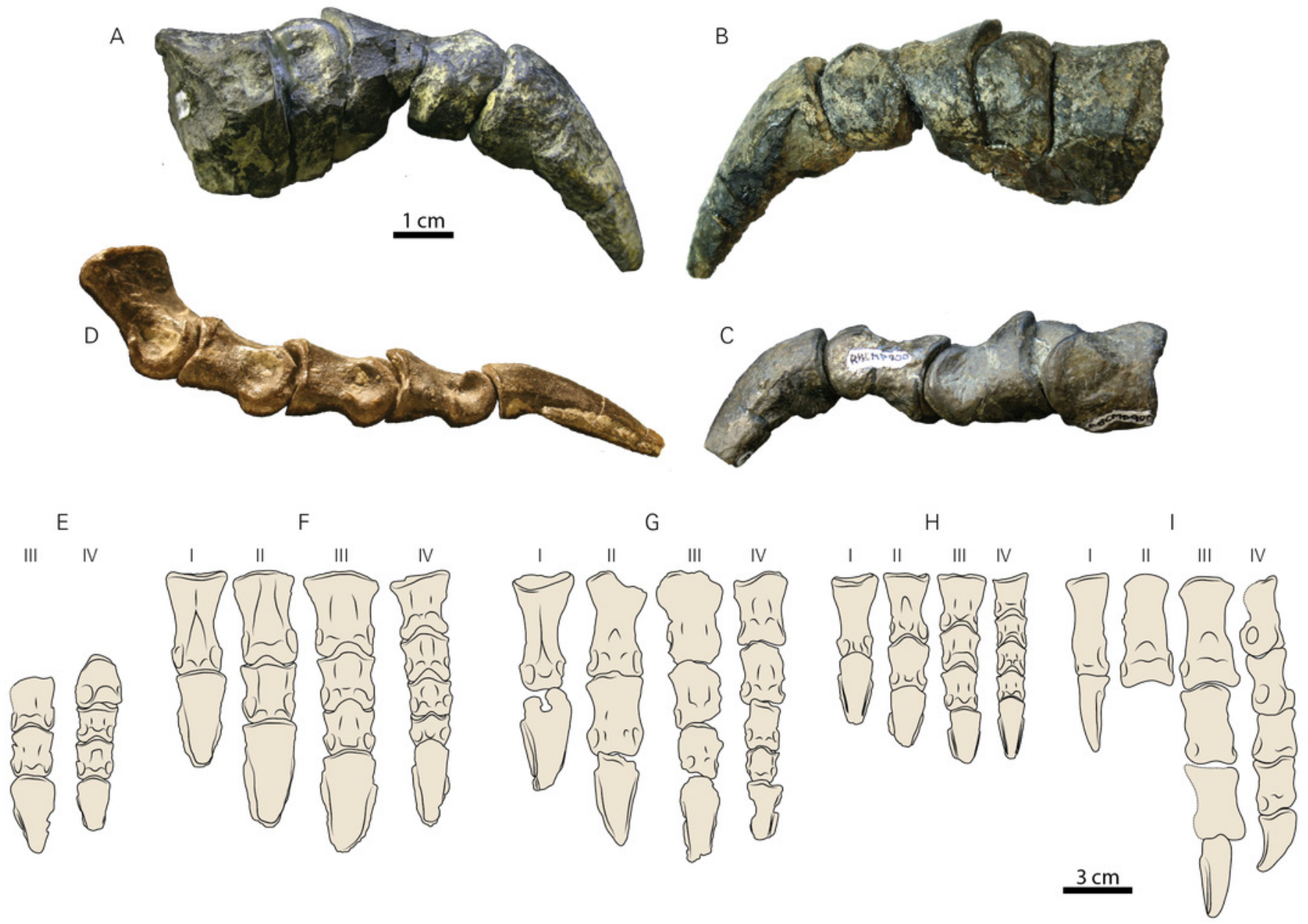
Figure 8

Results of the phylogenetic analyses.

Strict consensus trees showing the relationships of Ferrisaurus sustutensis within Ceratopsia: A) Strict consensus tree using the matrix modified from He et al. (2015). B) Strict consensus tree using the matrix from Morschhauser et al. (2019). 

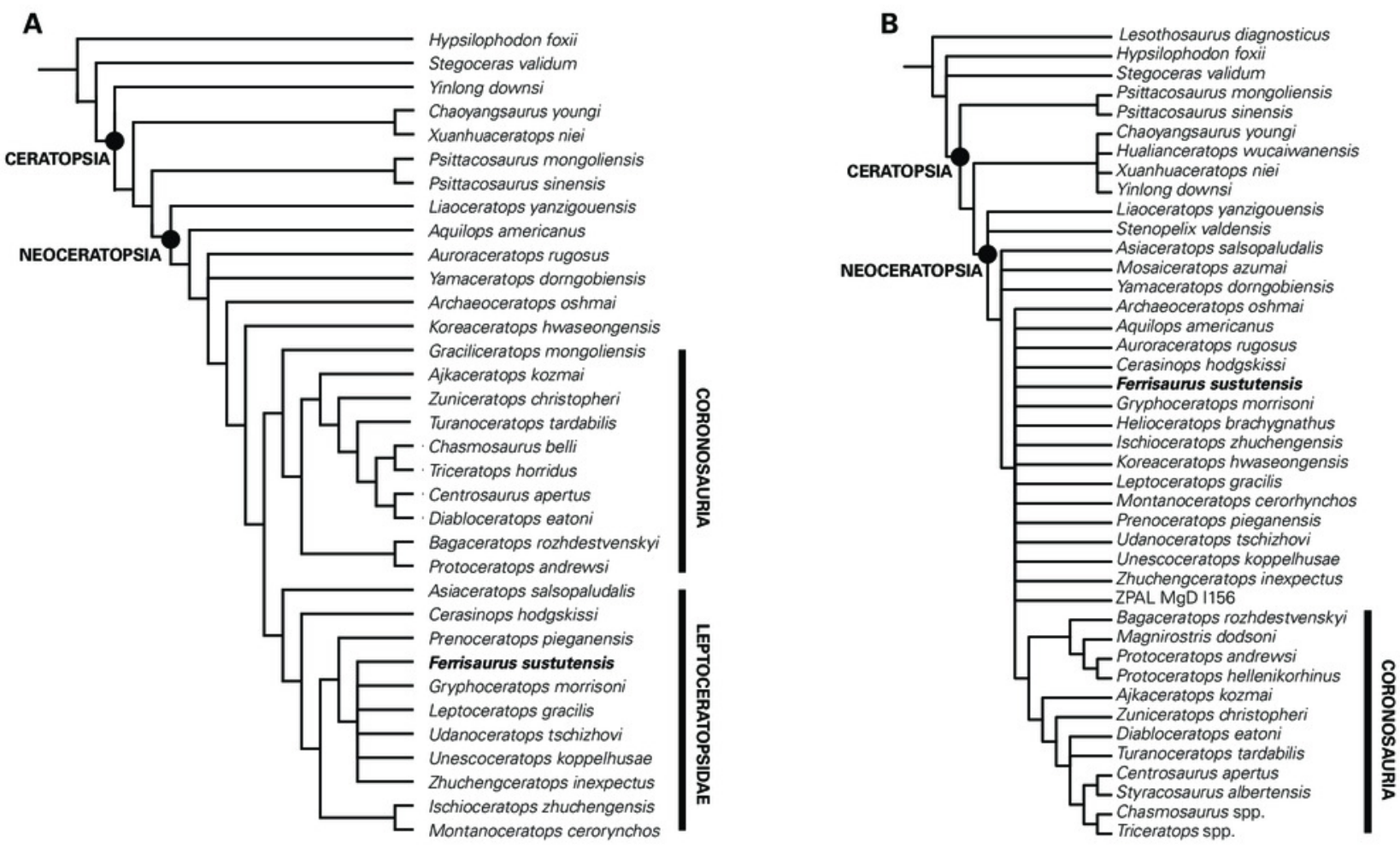


\section{Table 1 (on next page)}

Table 1: Selected measurements of forelimb and hindlimb elements in leptoceratopsids (mm). 
1 Table 1: Selected measurements of forelimb and hindlimb elements in leptoceratopsids ( $\mathrm{mm}$ ).

\begin{tabular}{|c|c|c|c|c|c|c|c|c|}
\hline \multirow[t]{2}{*}{ Taxon } & \multirow[t]{2}{*}{ Specimen } & \multirow{2}{*}{$\begin{array}{l}\text { Radius } \\
\text { Length }\end{array}$} & \multicolumn{2}{|l|}{ Ulna } & \multicolumn{2}{|l|}{ Tibia } & \multirow{2}{*}{$\begin{array}{l}\text { Fibula } \\
\text { Length }\end{array}$} & \multirow{2}{*}{$\begin{array}{l}\text { Measurement } \\
\text { source }\end{array}$} \\
\hline & & & Length & $\begin{array}{l}\text { Distal } \\
\text { width }\end{array}$ & Length & $\begin{array}{l}\text { Distal } \\
\text { width }\end{array}$ & & \\
\hline $\begin{array}{l}\text { Ferrisaurus } \\
\text { sustutensis }\end{array}$ & $\begin{array}{l}\text { RBCM } \\
\text { P900 }\end{array}$ & 135.0 & & 38.2 & & 90.1 & & $\begin{array}{l}\text { Direct } \\
\text { measurement }\end{array}$ \\
\hline \multirow[t]{3}{*}{$\begin{array}{l}\text { Cerasinops } \\
\text { hodgskissi }\end{array}$} & $\begin{array}{l}\text { MOR } 300 \\
R\end{array}$ & & 201.4 & $>32.6$ & 363.0 & $\sim 86.3$ & 337.0 & $\begin{array}{l}\text { Direct } \\
\text { measurement }\end{array}$ \\
\hline & $\begin{array}{l}\text { MOR } 300 \\
L\end{array}$ & & & & & 95.0 & & $\begin{array}{l}\text { Direct } \\
\text { measurement }\end{array}$ \\
\hline & $\begin{array}{l}\text { USNM } \\
13863\end{array}$ & & & & 200 & 62 & & $\begin{array}{l}\text { Brown and } \\
\text { Schlaikjer } \\
\text { (1942) }\end{array}$ \\
\hline $\begin{array}{l}\text { Ischioceratops } \\
\text { zhuchengensis }\end{array}$ & $\begin{array}{l}\text { ZCFM } \\
\text { V0016 }\end{array}$ & & & & 329 & & & He et al. (2015) \\
\hline \multirow[t]{5}{*}{$\begin{array}{l}\text { Leptoceratops } \\
\text { gracilis }\end{array}$} & $\begin{array}{l}\text { AMNH } \\
5205\end{array}$ & 167 & 224 & & & 117 & & $\begin{array}{l}\text { Sternberg } \\
(1951)\end{array}$ \\
\hline & $\begin{array}{l}\text { CMN } \\
8887\end{array}$ & 115 & & & 240 & & & $\begin{array}{l}\text { Sternberg } \\
(1951)\end{array}$ \\
\hline & $\begin{array}{l}\text { CMN } \\
8888\end{array}$ & 137 & & & 290 & & & $\begin{array}{l}\text { Sternberg } \\
\text { (1951) }\end{array}$ \\
\hline & $\begin{array}{l}\mathrm{CMN} \\
8889 \mathrm{~L}\end{array}$ & 160.5 & 202.5 & 35.7 & 323.0 & 87.9 & 293.0 & $\begin{array}{l}\text { Direct } \\
\text { measurement }\end{array}$ \\
\hline & PU 18133 & & & & $\sim 385$ & $\sim 78$ & & Ostrom (1978) \\
\hline \multirow[t]{2}{*}{$\begin{array}{l}\text { Montanoceratops } \\
\text { cerorhynchus }\end{array}$} & $\begin{array}{l}\text { AMNH } \\
5464\end{array}$ & & & & 355 & 102 & & $\begin{array}{l}\text { Brown and } \\
\text { Schlaikjer } \\
(1942)\end{array}$ \\
\hline & MOR 542 & & & 28.6 & 249.2 & 50.6 & 235.9 & $\begin{array}{l}\text { Direct } \\
\text { measurement }\end{array}$ \\
\hline $\begin{array}{l}\text { Prenoceratops } \\
\text { pieganensis }\end{array}$ & $\begin{array}{l}\text { TCM } \\
2003.1 .8\end{array}$ & & 143.3 & 19.1 & & & & $\begin{array}{l}\text { Direct } \\
\text { measurement }\end{array}$ \\
\hline
\end{tabular}

3

4

5

6

7

8 
Table 2 (on next page)

Table 2. Lengths of phalanges from pedal digits III and IV in leptoceratopsids (mm). 
1 Table 2. Lengths of phalanges from pedal digits III and IV in leptoceratopsids ( $\mathrm{mm}$ ).

\begin{tabular}{|c|c|c|c|c|c|c|c|c|c|}
\hline \multirow[t]{2}{*}{ Taxon } & \multirow[t]{2}{*}{ Specimen } & \multicolumn{3}{|l|}{ III } & \multicolumn{4}{|l|}{ IV } & \multirow{2}{*}{$\begin{array}{l}\text { Measurement } \\
\text { source }\end{array}$} \\
\hline & & 2 & 3 & 4 & 2 & 3 & 4 & 5 & \\
\hline $\begin{array}{l}\text { Ferrisaurus } \\
\text { sustutensis }\end{array}$ & $\begin{array}{l}\text { RBCM } \\
\text { P900 }\end{array}$ & 28.1 & 28.3 & 40.7 & 24.4 & 21.1 & 22.3 & 29.3 & $\begin{array}{l}\text { Direct } \\
\text { measurement }\end{array}$ \\
\hline \multirow[t]{3}{*}{$\begin{array}{l}\text { Cerasinops } \\
\text { hodgskissi }\end{array}$} & $\begin{array}{l}\text { MOR } 300 \\
R\end{array}$ & ?34.1 & ?27.9 & & & ?25.4 & & & $\begin{array}{l}\text { Direct } \\
\text { measurement }\end{array}$ \\
\hline & $\begin{array}{l}\text { MOR } 300 \\
L\end{array}$ & 36.5 & 29.8 & 44.9 & 33.5 & 27.2 & 20.1 & $>31.1$ & $\begin{array}{l}\text { Direct } \\
\text { measurement }\end{array}$ \\
\hline & $\begin{array}{l}\text { USNM } \\
13863\end{array}$ & 27.5 & 29.5 & 41 & 21 & 21 & 18.5 & & $\begin{array}{l}\text { Brown and } \\
\text { Schlaikjer } \\
(1942) \\
\end{array}$ \\
\hline \multirow[t]{3}{*}{$\begin{array}{l}\text { Leptoceratops } \\
\text { gracilis }\end{array}$} & $\begin{array}{l}\text { CMN } \\
8887\end{array}$ & 21.3 & 16.5 & 32.2 & 18.4 & 14.4 & 13.7 & 24.9 & $\begin{array}{l}\text { Direct } \\
\text { measurement } \\
\text { from cast }\end{array}$ \\
\hline & $\begin{array}{l}\text { CMN } \\
8889 \mathrm{R}\end{array}$ & 31.9 & 29.6 & 51.0 & 29.4 & 25.1 & 22.0 & 44.1 & $\begin{array}{l}\text { Direct } \\
\text { measurement }\end{array}$ \\
\hline & PU 18133 & 40 & 30 & & 32 & $\sim 26$ & $\sim 20$ & & Ostrom (1978) \\
\hline \multirow[t]{2}{*}{$\begin{array}{l}\text { Montanoceratops } \\
\text { cerorhynchus }\end{array}$} & $\begin{array}{l}\text { AMNH } \\
5464\end{array}$ & 33 & & 68 & & & & & $\begin{array}{l}\text { Brown and } \\
\text { Schlaikjer } \\
\text { (1942) }\end{array}$ \\
\hline & MOR 542 & 28.4 & 25.1 & $\sim 29.0$ & 20.4 & 21.0 & 19.1 & 34.0 & $\begin{array}{l}\text { Direct } \\
\text { measurement }\end{array}$ \\
\hline
\end{tabular}

2 